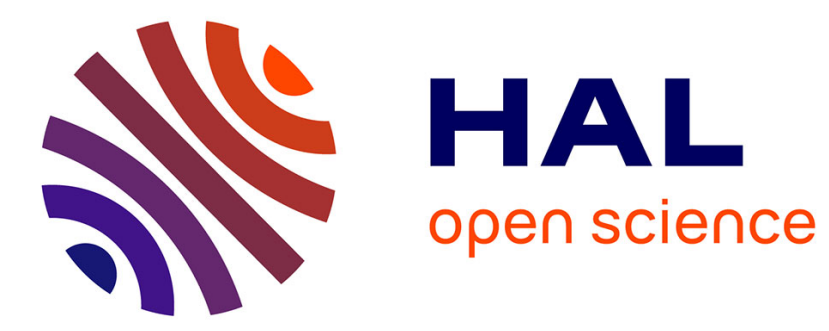

\title{
Fully ionized nanosecond discharges in air: the thermal spark
}

Nicolas Minesi, S Stepanyan, Pierre Mariotto, Gabi Daniel Stancu, Christophe

Laux

\section{- To cite this version:}

Nicolas Minesi, S Stepanyan, Pierre Mariotto, Gabi Daniel Stancu, Christophe Laux. Fully ionized nanosecond discharges in air: the thermal spark. Plasma Sources Science and Technology, 2020, 10.1088/1361-6595/ab94d3 . hal-02614662

\section{HAL Id: hal-02614662 \\ https://hal.science/hal-02614662}

Submitted on 4 Jun 2020

HAL is a multi-disciplinary open access archive for the deposit and dissemination of scientific research documents, whether they are published or not. The documents may come from teaching and research institutions in France or abroad, or from public or private research centers.
L'archive ouverte pluridisciplinaire HAL, est destinée au dépôt et à la diffusion de documents scientifiques de niveau recherche, publiés ou non, émanant des établissements d'enseignement et de recherche français ou étrangers, des laboratoires publics ou privés. 
1 Fully ionized nanosecond discharges in air: the thermal spark

Laboratoire EM2C, CNRS, CentraleSupélec, Université Paris-Saclay, 3 rue Joliot Curie, 91190 Gif-sur-Yvette, France

5

6

Abstract:

The formation and decay of the thermal spark generated by a single nanosecond highvoltage pulse between pin electrodes are characterized in this study. The influence of air pressure in the range $50-1000$ mbar is investigated at $300 \mathrm{~K}$. By performing short-gate imaging and Optical Emission Spectroscopy (OES), we find that the thermal sparks exhibit an intense emission from excited electronic states of $\mathrm{N}^{+}$, in contrast with non-thermal sparks for which the emission is dominated by electronic transitions of $\mathrm{N}_{2}$. Spark thermalization consists of the following steps: (i) partial ionization of the plasma channel accompanied by $\mathrm{N}_{2}$ emission, (ii) creation of a fully ionized filament at the cathode characterized by $\mathrm{N}^{+}$emission, (iii) formation of a fully ionized filament at the anode, (iv) propagation of these filaments toward the middle of the interelectrode gap, and (v) merging of the filaments. The formation of the filaments, steps (ii) and (iii), occurs at subnanosecond timescales. The propagation speed of the filaments is on the order of $10^{4} \mathrm{~m} / \mathrm{s}$ during step (iv). For the 1-bar condition, the electron number densities are measured from the Stark broadening of $\mathrm{N}^{+}$and $\mathrm{H}_{\alpha}$ lines, with spatial and temporal resolution. The electron temperature is also determined, from the relative emission intensity of $\mathrm{N}^{+}$excited states, attaining a peak value of $48,000 \mathrm{~K}$. In the post-discharge, the electron number density decays from $4 \times 10^{19}$ to $2 \times 10^{18} \mathrm{~cm}^{-3}$ in $100 \mathrm{~ns}$. We show that this decay curve can be interpreted as the isentropic expansion of a plasma in chemical equilibrium. Comparisons with previous experiments from the literature support this conclusion. Expressions for the Van der Waals and resonant broadenings of $\mathrm{H}_{\alpha}, \mathrm{H}_{\beta}$, and several lines of $\mathrm{O}, \mathrm{O}^{+}, \mathrm{N}$ and, $\mathrm{N}^{+}$ are derived in the appendix.

Keywords: electron recombination, spark ignition, spark breakdown, non-equilibrium spark, filaments, spectral line broadening, plasma diagnostics 
$1 \quad 1$ Introduction

2 As shown by Pai et al. [1], three regimes of Nanosecond Repetitively Pulsed (NRP)

3 discharges can be distinguished in air: (i) NRP-corona, (ii) NRP-glow, and (iii) NRP-spark.

4 Typical emission spectra of these NRP-corona, glow and spark discharges in air are

5 dominated by $\mathrm{N}_{2}(\mathrm{~B})$ and $\mathrm{N}_{2}(\mathrm{C})$ emission. Emission of $\mathrm{O}$ and $\mathrm{N}_{2}{ }^{+}(\mathrm{B})$ is also present in the

6 glow and spark regimes. Criteria for the corona-glow and glow-spark transitions were

7 proposed in Ref. [1]. The corona and glow discharges are characterized by high voltages,

8 low conduction currents $(<1 \mathrm{~A}$ ), and low deposited energies (less than $100 \mu \mathrm{J}$ per pulse

9 [1]). These two nonequilibrium discharges produce moderate gas heating (less than $200 \mathrm{~K}$

10 [2]) and relatively low electron number densities (less than $10^{13} \mathrm{~cm}^{-3}$ in air at atmospheric

11 pressure [2]). Corona discharges are confined near the electrodes, whereas the glow and

12 the spark fill the entire interelectrode space. The spark is characterized by a much higher

13 current (> tens of A) and higher energy deposition (> $1 \mathrm{~mJ}$ per mm per pulse [1,3,4]). The

14 gas temperature in the nanosecond spark was found to increase by a few thousand kelvin

15 in a few tens of nanoseconds due to the ultrafast heating mechanism [4-8]. Although the

16 electron number density reaches $10^{15}-10^{16} \mathrm{~cm}^{-3}$ in the nanosecond spark [5], the plasma

17 does not reach equilibrium.

18 In a recent study of single microsecond pulses in ambient air, Lo et al. [9] observed a 19 complete ionization of the gas with high electron number densities $\left(10^{18}-10^{19} \mathrm{~cm}^{-3}\right)$ that 20 do not correspond to any of the discharge regimes described above. The electron number 21 density, $n_{e}$, was measured from the Stark broadening of $\mathrm{N}^{+}$lines. The transition from the partially to fully ionized plasma, called "streamer-to-arc" was shorter than $5 \mathrm{~ns}$. The emission spectrum observed in Ref. [9] is first dominated by $\mathrm{N}_{2}(\mathrm{C} \rightarrow \mathrm{B})$ emission (as in the case of the NRP-spark [1]) and then by continuum emission and lines of $\mathrm{N}^{+}$. This abrupt change of spectrum corresponds to the transition from a partially to a fully ionized plasma. The gas temperature before the transition was measured from $\mathrm{N}_{2}(\mathrm{C} \rightarrow \mathrm{B})$ rotational lines and after the transition using a Boltzmann plot of the $\mathrm{N}^{+}$lines. These measurements showed a dramatic rise of the gas temperature, from $1200 \mathrm{~K}$ to $36,000 \mathrm{~K}$ in less than $5 \mathrm{~ns}$. Observations of fully ionized plasmas under nanosecond discharges were also reported in water vapor $[10,11]$ and in air $[12,13]$. A similar transition, called "streamer-to-filament", was also observed for a 20-ns Surface Dielectric Barrier Discharge (SDBD) [14,15]. 
Shcherbanev et al. [14] observed a transition from molecular emission to a continuumdominated spectrum accompanied by an "enormously large" broadening of $\mathrm{H}_{\alpha}(20-30 \mathrm{~nm})$ and $\mathrm{O}_{777 \mathrm{~nm}}(5 \mathrm{~nm})$ lines. No emission of $\mathrm{N}^{+}$was recorded at these conditions. The same authors recently measured electron number densities $n_{e}=10^{18}-10^{19} \mathrm{~cm}^{-3}$ in a similar configuration [16]. Similar results were obtained in Ref. [17] for a 50- $\mu$ s SDBD in ambient air. The authors of Ref. [17] showed that the "contraction" of the discharge channel is associated with the appearance of a continuum spectrum and lines of $\mathrm{N}^{+}, \mathrm{N}, \mathrm{O}$, and $\mathrm{H}_{\alpha}$. Observations of $\mathrm{N}^{+}$emission for nanosecond discharges in pin-to-pin configuration have also been presented by Shao et al. [18,19]. These authors showed that the "constriction" was accompanied by the emission of spots at the electrodes. In 1977, Stritzke et al. [20] measured the distribution of the electron number density before and during the transition from an $\mathrm{N}_{2}$ - to an $\mathrm{N}^{+}$-dominated emission. The map of the electron temperature during and after the transition was measured using lines of $\mathrm{N}^{+}, \mathrm{N}^{++}, \mathrm{N}^{+++}$, and $\mathrm{N}^{++++}$. For the conditions of Ref. [20], the emission of $\mathrm{N}^{+}$appeared at electron number densities above $10^{16} \mathrm{~cm}^{-3}$, and the electron temperature reached 50,000 K after the transition. In 1977 also, Albrecht et al. [21] measured with Stark broadening the electron number density in a 1-mm discharge generated in $\mathrm{N}_{2}$ at 1 bar. The spatially resolved emission spectra of $\mathrm{N}_{2}$ and $\mathrm{N}^{+}$were used to obtain the gas and electron temperatures, respectively. In addition, the hydrodynamic effects of the discharge were measured by laser interferometry. Parkevich et al. [22-24] recently measured the full ionization of nanosecond discharges by laser interferometry. In their conditions [23], they showed that the discharge propagated in the form of more than ten fully ionized filaments of diameter in the range $10-50 \mu \mathrm{m}$.

Because of their short duration, nanosecond discharges are often assumed to be nonequilibrium. However, such high electron number densities $\left(10^{18}-10^{19} \mathrm{~cm}^{-3}\right)$ and temperatures $(30,000-50,000 \mathrm{~K})$ are sufficient to reach Local Thermal Equilibrium (LTE) thanks to Coulomb collisions [20,25]. The state of the plasma after the transition is often called differently in the literature: "spark" in [9,18-20,25], "filament" in [14-16], "constricted/filamentary" plasma in [17-19]. In this work, we will call "thermal spark" the transient fully ionized plasma generated by a nanosecond pulse in order to (1) emphasize the equilibrium state of the plasma (thermal), and (2) be consistent with the literature of spark transient discharges [26] (spark). 
2 Currently, there is no complete description in the literature of the thermal spark formation and decay. Recent publications [16,27] emphasized the role of $\mathrm{N}_{2}$ and $\mathrm{N}$ excited states in

4 the ionization process, but the mechanism of propagation of the fully ionized plasma is still 5 under investigation. The post-discharge of the thermal spark is also poorly understood.

6 Orriere et al. [13] suggested that the decay of $n_{e}$ in the post-discharge may be due to three7 body recombination of $\mathrm{N}^{+}$.

In the present work, our objective is to describe the thermal spark formation and to determine the main electron decay processes in the post-discharge. The paper is organized as follows: Section 2 describes the experimental setup and Section 3 presents a study of the influence of pressure on the thermal spark formation. In Section 4 our measurements of the electron number density are described and the decay of the electron number density

14 in the post-discharge is analyzed. In Section 5, a comparison with other thermal sparks

15 found in the literature is discussed, and in Section 6, the thermal spark is compared with and $\mathrm{H}_{\beta}$ ) and compare their contribution to the total line broadening.

\section{Experimental setup:}

An overview of the experimental setup is shown in Figure 1. The experiments presented here are performed with nanosecond discharges initiated by single high-voltage pulses between pin-to-pin tungsten electrodes. The radius of curvature of the electrodes is approximately $300 \mu \mathrm{m}$, and the inter-electrode distance is 0.9 or $2 \mathrm{~mm}$. The discharges are initiated by a generator (FID FPG 30-100MC4K) producing pulses of 10-ns duration, amplitudes up to $30 \mathrm{kV}$ and Pulse Repetition Frequencies (PRF) up to $100 \mathrm{kHz}$. For the experiments at various pressures presented in Section 3, a positive pulse is sent to the anode and a negative pulse to the cathode. For the experiments presented in Section 4, practical reasons dictated the use of only a negative pulse at the cathode and a grounded anode. A summary of these two experimental configurations is presented in Table 1. Low PRFs of 
10 and $50 \mathrm{~Hz}$ are used to reproduce the conditions of single pulse experiments. The

2 electrical characteristics of the discharge are monitored by two high voltage probes (LeCroy PPE20kV) and two current probes (Pearson 6585) connected to an oscilloscope (Lecroy HDO 6104 or Lecroy Wavepro 7100A). The high-voltage generator and the 5 camera are synchronized with a gate-and-delay generator (BNC Model 575). The electrodes are placed inside a sealed cell in order to control the pressure (50 - 1000 mbar) and gas composition (pure air or a mixture of air with $1.6 \%$ of hydrogen). In previous 8 publications [8,28], the voltage and current probes were placed at the electrodes. In the present work, as in Refs. [3,29], the current and voltage measurements are performed about midway of a 7-m coaxial cable. The voltage probes are connected to the core of the coaxial cables and the measured current waveform is synchronized with the measured incident voltage waveform. The measured current is proportional to the voltage in the cable, which has an impedance of $75 \Omega$. These measurements are used to monitor the energy incident and reflected on the load (electrodes and plasma). Figure 2 presents typical voltage and current waveforms for a $5.5-\mathrm{kV}$ generated pulse sent to a 2-mm interelectrode gap (setup \#2 in Table 1). The cable length induces a delay of $20 \mathrm{~ns}$ between the electrical and the OES measurements. This delay was considered for the synchronization of the voltage and emission signals. The energy displayed at the top of Figure 2 is the integral over time of the product of voltage and current. In the case of breakdown (black solid curves), the generated pulse is measured by the probes at $t=-20 \mathrm{~ns}$ and carries approximately $3.5 \mathrm{~mJ}$. About $1 \mathrm{~mJ}$ of this energy is reflected to the generator, as shown by the energy decay in the pulse between the electrodes and the generator do not change the energy deposited in the plasma by more than $10 \%$. If a positive pulse and a negative pulse are sent to the anode and the cathode, respectively, the energy is measured in both cables and summed. The applied voltage at the cathode is the sum of the incident and reflected pulses and results in a maximum voltage of $U_{\max }=-10 \mathrm{kV}$. We also confirmed that there are no significant losses in the electrical circuit if breakdown does not occur. The gray dashed curve in Figure 2 presents the waveforms for the case when breakdown is prevented by increasing the pressure to $4 \mathrm{~atm}$. In this case, the incident energy $(3.5 \mathrm{~mJ})$ is sent to the electrode $(t=-20$ 


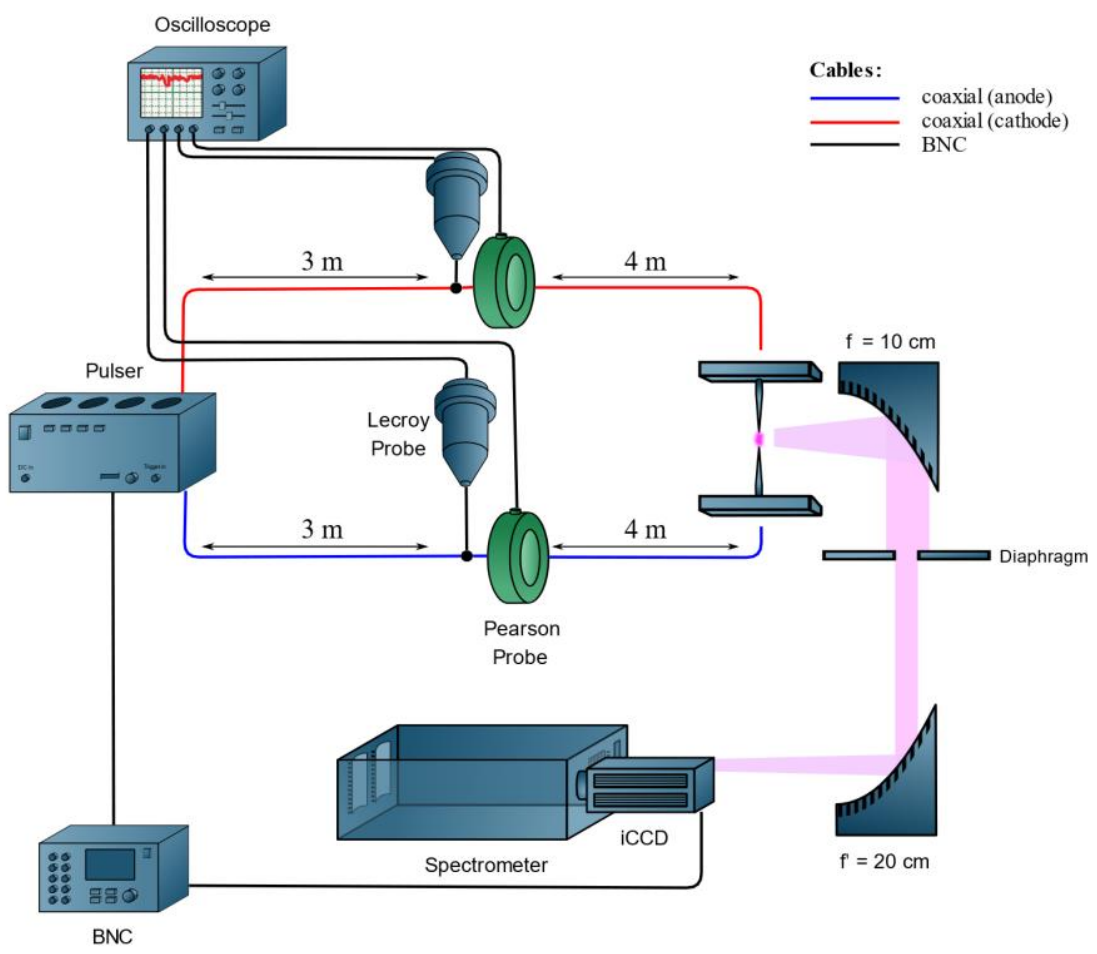

3

Figure 1 Experimental setup for the cathode-anode configuration. In the cathode-ground configuration, only the red coaxial cable is used, and the other electrode is grounded.

An Optical Emission Spectroscopy (OES) set-up is used to measure electron number densities and electron temperatures. The discharge is placed at the focal point of an offaxis parabolic mirror $(f=10 \mathrm{~cm})$ as shown in Figure 1. The collimated light from the plasma is then refocused by a second parabolic mirror $(f=20 \mathrm{~cm}$ ) onto the monochromator (Acton 500i) entrance slit. The monochromator is equipped with two gratings of 300 and $1800 \mathrm{gr} / \mathrm{mm}$, both blazed at $500 \mathrm{~nm}$. An ICCD camera (Pi-MAX4) coupled to the monochromator is used to record the spectra with a minimum gate of $450 \mathrm{ps}$. The pitch of the pixels on the ICCD is $13 \mu \mathrm{m}$. A HeNe laser (Thorlabs at $632.8 \mathrm{~nm}$ ) is used to determine the instrumental broadening of the OES system. The discharge reproducibility is sufficient to perform phase-locked acquisitions for imaging and OES experiments because the temporal jitter of the pulse is below $0.5 \mathrm{~ns}$. Discharge imaging is performed using the zeroth order of diffraction of the monochromator grating. The axis of the plasma channel shifts typically by $\pm 50 \mu \mathrm{m}$ from shot to shot. A 150 - $\mu \mathrm{m}$ slit, aligned with the interelectrode axis, 
1 is used to capture the entire emission of the discharge. The width of the slit is sufficient to

2 capture the discharge even with its fluctuations in position. The overall optical system has

3 a spatial resolution of about $8 \mu \mathrm{m}$ per pixel.

4

$5 \quad$ Table 1 Summary of the two configurations used in this work.

\begin{tabular}{|l|l|l|}
\hline Configuration & Setup \#1 & Setup \#2 \\
\hline Electrode polarities & Cathode-Anode & Cathode-Ground \\
\hline Interelectrode gap & $0.9 \mathrm{~mm}$ & $2 \mathrm{~mm}$ \\
\hline Deposited energy & $2.5-3.5 \mathrm{~mJ}$ per pulse & $2.5 \mathrm{~mJ}$ per pulse \\
\hline $\begin{array}{l}\text { Amplitude of } \\
\text { incident pulse }\end{array}$ & $\begin{array}{l}\text { Cathode: }-5 \mathrm{kV} \\
\text { Anode: }+3.5 \mathrm{kV}\end{array}$ & Cathode: $-5.5 \mathrm{kV}$ \\
\hline Pressure & $58 \mathrm{mbar}-1 \mathrm{bar}$ & $1 \mathrm{bar}$ \\
\hline Gas & Ambient air & Ambient air $+1.6 \%$ of $\mathrm{H}_{2}$ \\
\hline Study of: & Effect of pressure & Electron number density evolution \\
\hline
\end{tabular}

6 


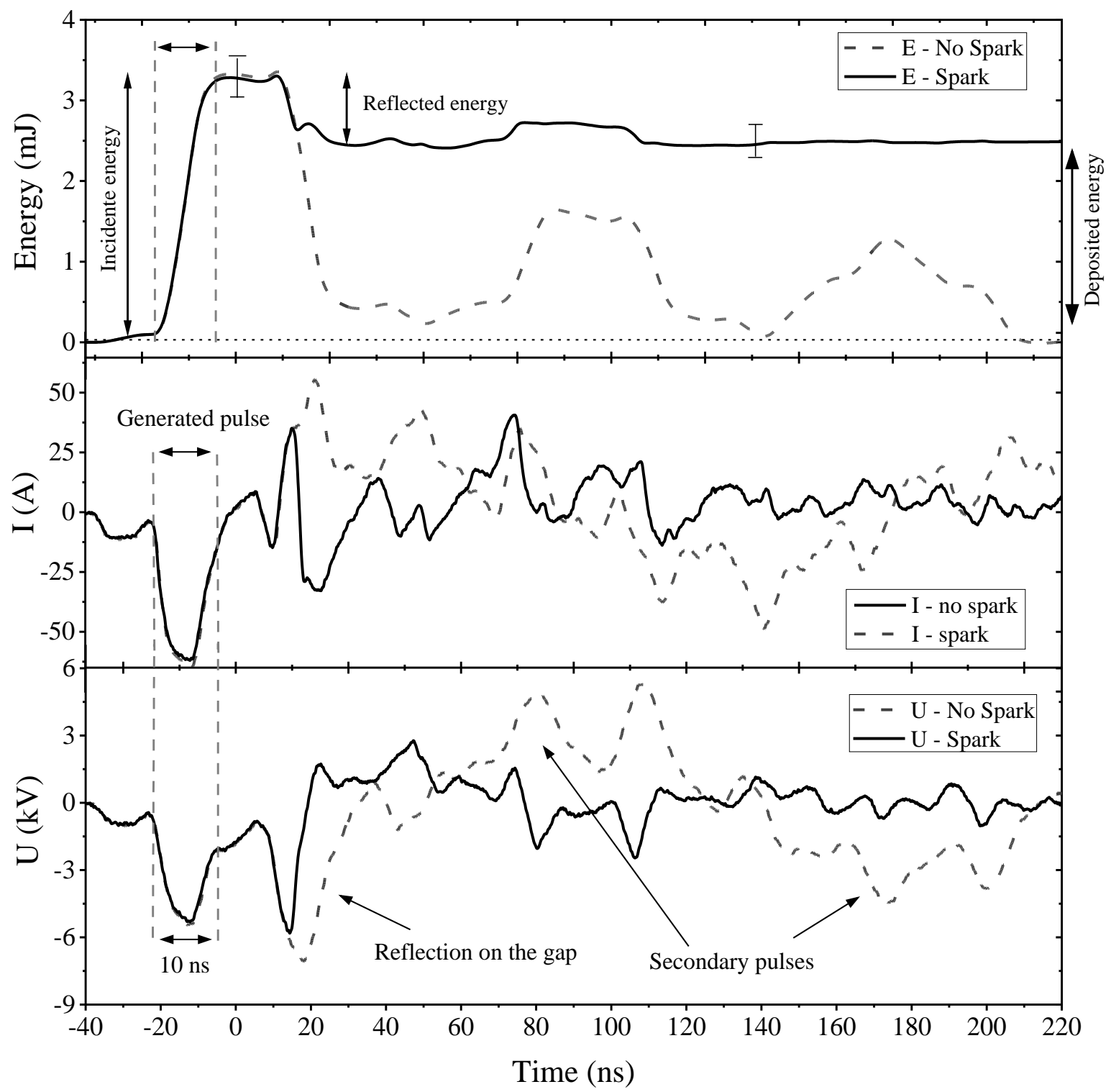

Figure 2 Voltage, current and energy waveforms for the cathode-ground configuration in air in a 2-mm gap (setup \#2). A thermal spark is obtained at atmospheric pressure (solid black lines). At 4 atm, the breakdown is prevented (dashed gray lines).

63 Imaging of nanosecond discharges in the pressure range $58-1000$ mbar

8 This section presents observations of the thermal spark produced by a single nanosecond

9 discharge in the cathode-anode configuration (setup \#1). The total emission images shown

10 in Figure 3 are obtained with a Canon 5D Mrk II. The exposure time of the camera is

11100 milliseconds, which is longer than the discharge duration and its afterglow. At low 
pressure (58 and 80 mbar), the discharge forms a bright channel between the pins and a

2 corona covering mostly the cathode (top electrode in Figure 3). The emission radius (Half

3 Width at Half Maximum, noted HWHM) of the channel is $250 \mu \mathrm{m}$ at $58 \mathrm{mbar}$. The bright

4 cathode and anode spots have a typical radius between 50 and $150 \mu \mathrm{m}$. When the pressure

5 increases to one atmosphere, the visible channel radius reduces to $140 \mu \mathrm{m}$, the spots and

6 the corona disappear, and the color of the discharge changes from purple to white. These

7 spots were already reported in Ref. [19,24].
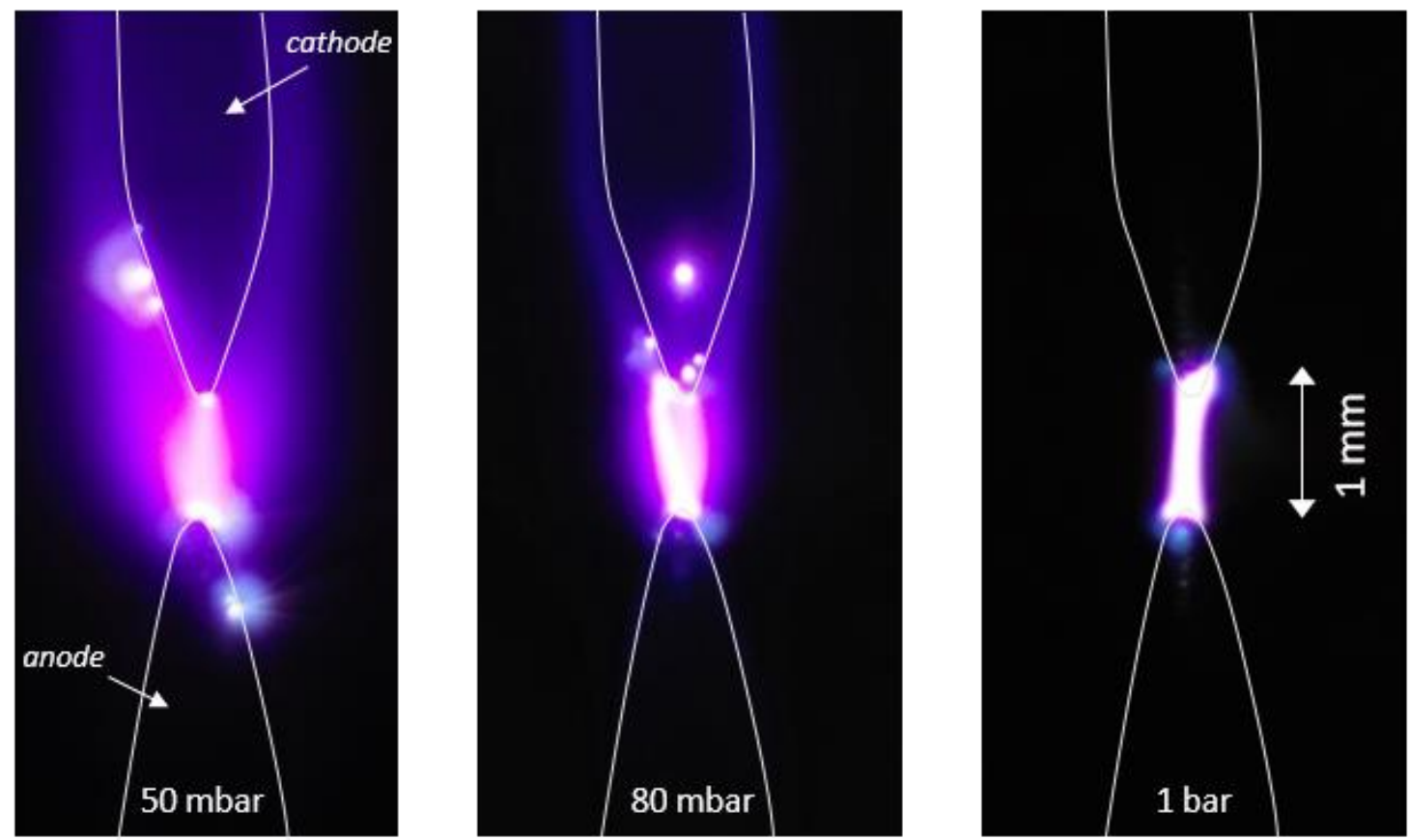

Figure 3 Photographs of single ns-discharges in real colors (Canon 5D Mrk II) at 50 mbar, 80 mbar and 1 bar. The electrode contours are represented by the white lines. The distance between the electrodes (top: cathode, bottom: anode) is $1 \mathrm{~mm}$. The intensity scale is adjusted in each picture. Cathode spots are visible at 50 mbar and 80 mbar. An anode spot is visible at 50 mbar.

To observe the evolution of the plasma during the applied pulse at different pressures, ICCD imaging and OES are performed with a temporal resolution of $480 \mathrm{ps}$. The discharge emission is recorded from 0 to $100 \mathrm{~ns}$ in steps of $0.5 \mathrm{~ns}$. Figure 4 shows the map of total emission obtained for a single pulse nanosecond discharge initiated in ambient air at 58, 240, 600 and 1000 mbar. The distance between the electrodes is $0.9 \mathrm{~mm}$. The intensity scale is logarithmic and identical in all images. 


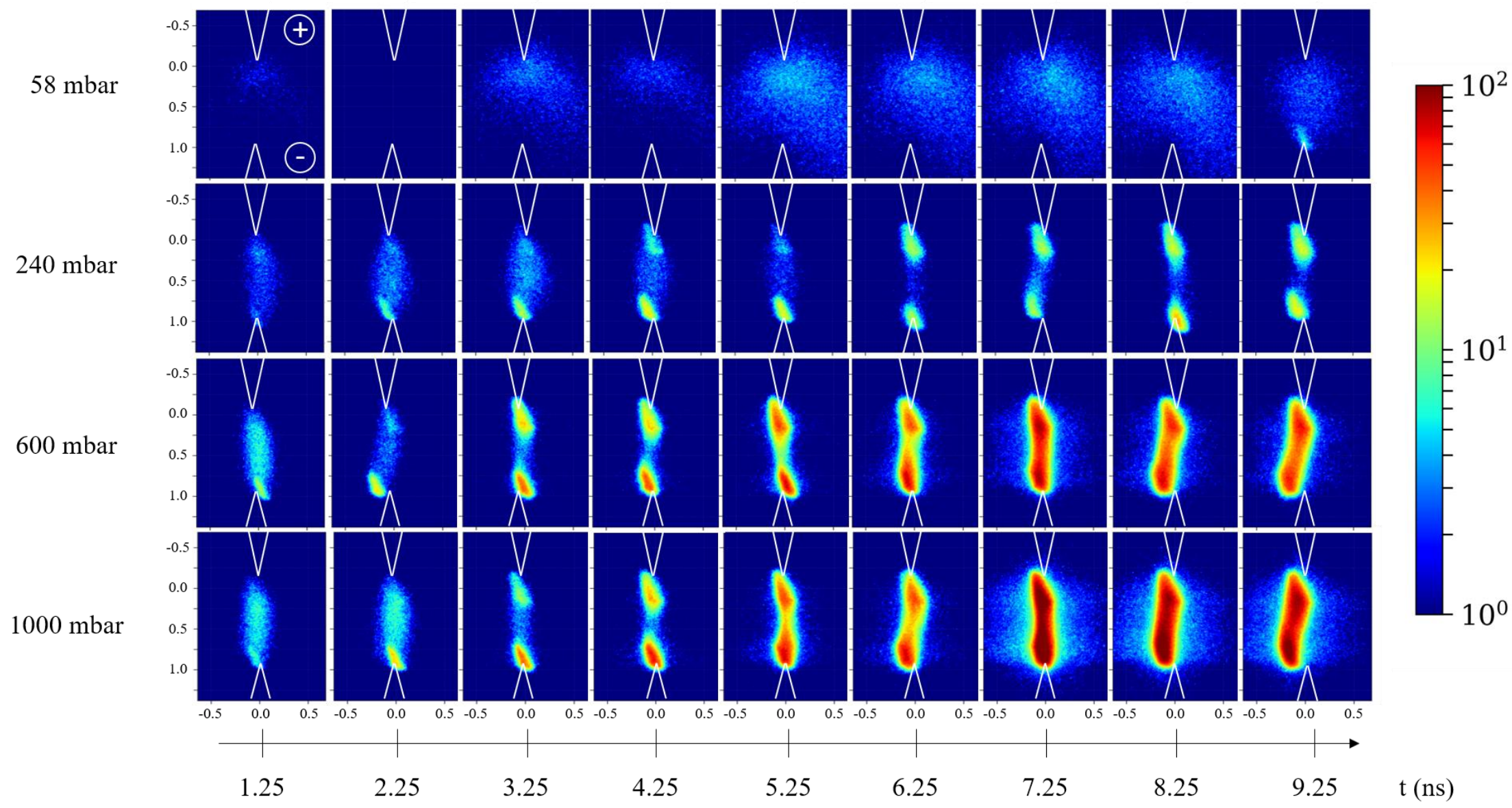

Figure 4 Phase-locked evolution of the total recorded intensity in a logarithmic scale of a nanosecond discharge (setup \#1, inter-electrode gap of 0.9 mm) at 58, 240, 600 and 1000 mbar. The physical distance is shown on all pictures in mm and the position of the electrodes is represented by white lines. The time step is $1 \mathrm{~ns}$ with camera gates of $0.48 \mathrm{~ns}$ (for example the measurement at $4.25 \mathrm{~ns}$ is recorded from 4 to $4.5 \mathrm{~ns}$ ). The cathode and the anode are respectively marked by - and + signs in the top left corner. These images are all single shot and are not Abel-inverted. 
At 58 mbar, a streamer propagates from the anode to the cathode. No sharp increase in the emission is recorded during the propagation phase. At the end of the pulse $(9-10 \mathrm{~ns})$, a bright filament appears at the cathode.

At 240 mbar, the streamer propagation is faster and cannot be resolved with the present camera gate (i.e. the interelectrode gap is filled within $0.5 \mathrm{~ns}$ ). A cathode filament appears at about $t=$ $2.25 \mathrm{~ns}$ and an anode filament at about $t=4.25 \mathrm{~ns}$. These $250-\mu \mathrm{m}$ long filaments form within less than $0.5 \mathrm{~ns}$. Therefore, their formation cannot be resolved with the camera. This means that either the filaments are created simultaneously in the entire volume or that they propagate from the electrode surface toward the middle of the gap at a speed above $5 \times 10^{5} \mathrm{~m} / \mathrm{s}(0.5 \mathrm{~mm} / \mathrm{ns})$.

At pressures below 450 mbar, the filaments do not propagate toward the middle of the gap after they are formed. Above 600 mbar, however, the filaments start to propagate toward each other and rapidly merge (in less than $2 \mathrm{~ns}$ ) in the middle of the gap. The length and diameter of the filaments are independent of the pressure in the studied conditions. Figure 5 presents the propagation speed of the filaments versus pressure. One can see that the cathode filament is typically faster than the anode one $\left(\sim 5 \times 10^{4} \mathrm{~m} / \mathrm{s}\right.$ versus $\left.\sim 2.5 \times 10^{4} \mathrm{~m} / \mathrm{s}\right)$.

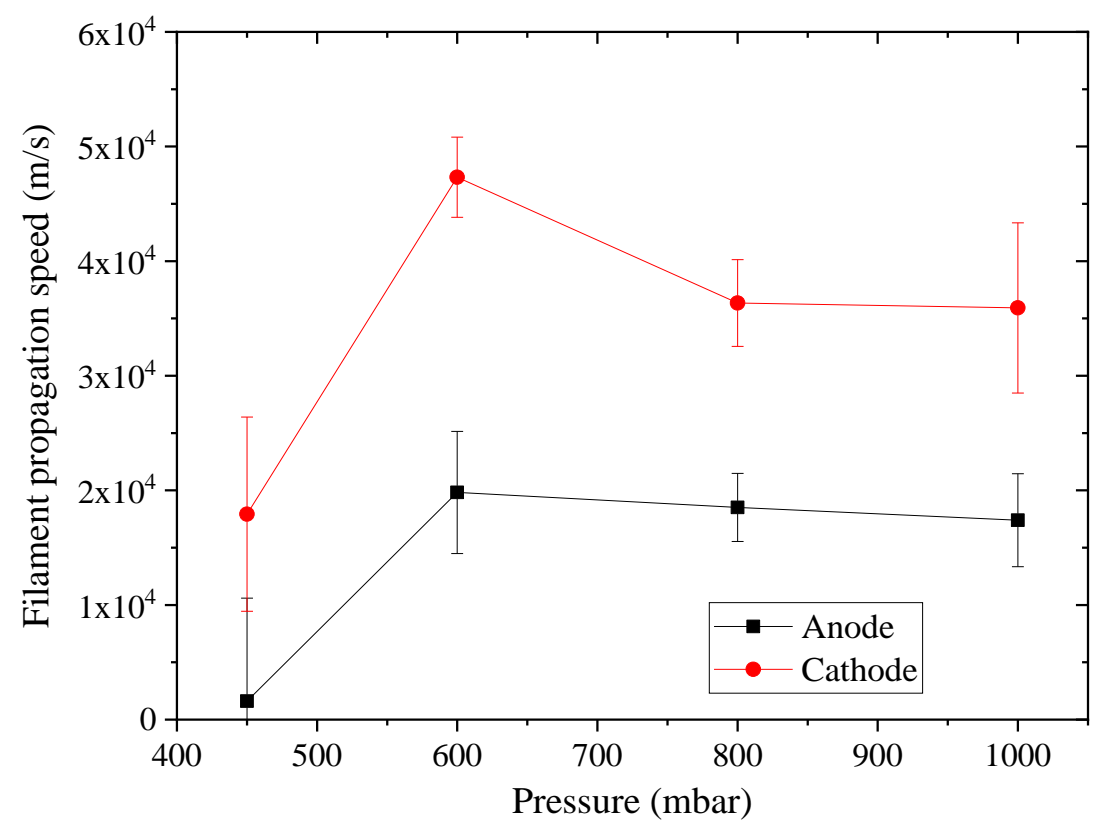

Figure 5 Propagation speed of the filaments from 400 mbar to 1 bar. At the anode, the speed is relatively constant $\approx 20 \mu \mathrm{m} . n \mathrm{~s}^{-1}$. The speed of propagation of the cathode filament is of the same order of magnitude, with a peak at $5 \times 10^{4} \mathrm{~m} \cdot \mathrm{s}^{-1}=50 \mu \mathrm{m} . \mathrm{ns}^{-1}$. 
The discharge spectra integrated over the pulse duration and plasma volume are shown in Figure 6. The streamer emission (i.e. not the filaments) at low pressure is mainly due to the $\mathrm{N}_{2}(\mathrm{C} \rightarrow \mathrm{B})$ and $\mathrm{N}_{2}{ }^{+}(\mathrm{B} \rightarrow \mathrm{X})$ transitions. The filaments that appear at higher pressure are characterized by a continuum emission. Several intense emission lines around $500 \mathrm{~nm}$ can also be identified, corresponding to transitions from $\mathrm{N}^{+}\left({ }^{3} \mathrm{~S},{ }^{3} \mathrm{P}^{0},{ }^{3} \mathrm{~F}^{0}\right)$ [31]. Shcherbanev et al. [16] also showed that the constriction of an SDBD is accompanied by a transition from a broad $(\sim 40 \mu \mathrm{m})$ channel with $\mathrm{N}_{2}$ emission to a thin channel $(\sim 18 \mu \mathrm{m})$ with $\mathrm{N}^{+}$emission.

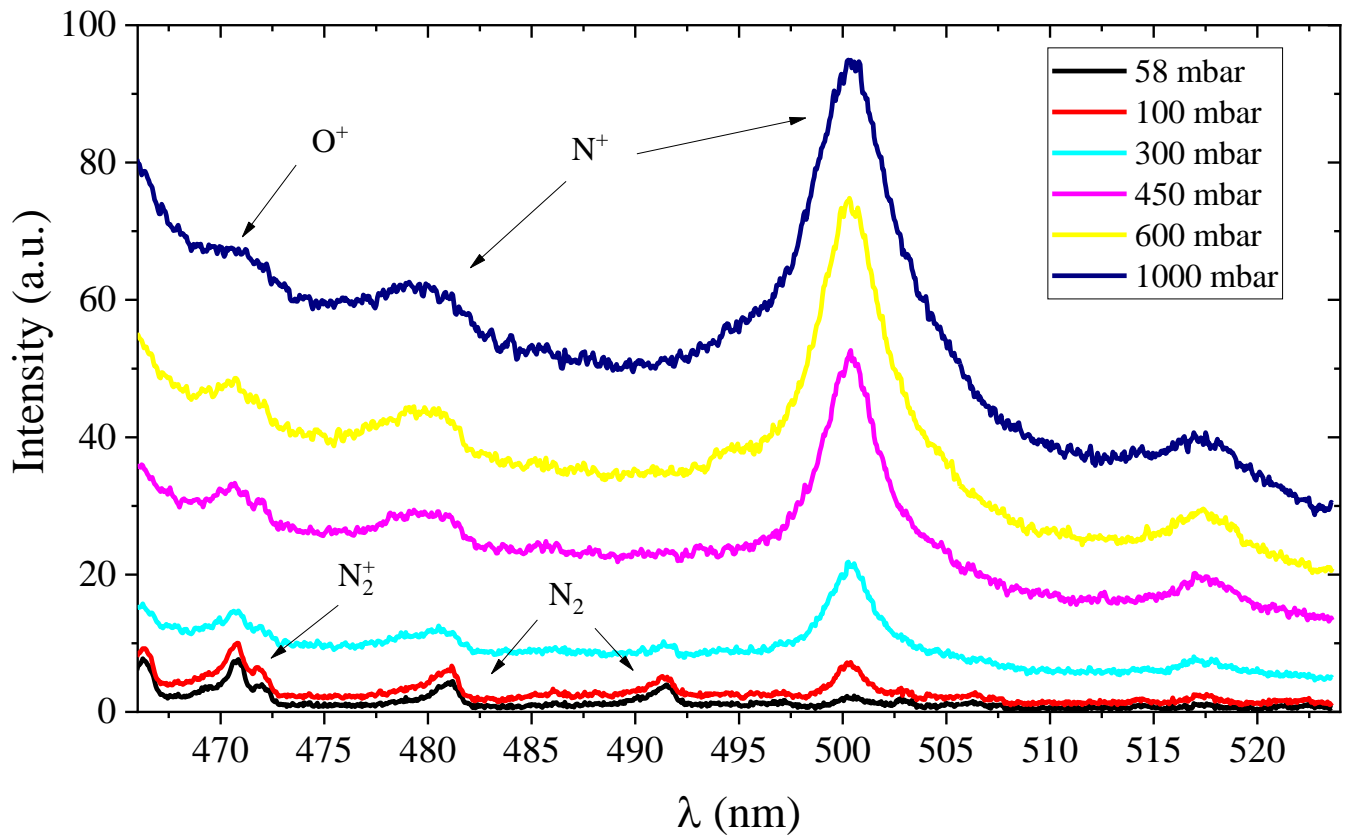

Figure 6 Measured emission spectra (middle of the gap) integrated from $t=0$ to $10 \mathrm{~ns}$ at several pressures. The interelectrode gap is $0.9 \mathrm{~mm}$ (setup \#1). For the sake of clarity, only six spectra are displayed.

The data presented in Figure 4 and Figure 6 show that the thermal spark formation consists of the followings steps: (i) formation of a preionized channel between the electrodes; (ii) creation of a 250- $\mu \mathrm{m}$ long filament at the cathode characterized by $\mathrm{N}^{+}$emission; (iii) $1-2$ nanoseconds later, creation of a $250-\mu \mathrm{m}$ filament at the anode; (iv) the filaments start propagating to the middle of the gap at a speed $\sim 10^{4} \mathrm{~m} / \mathrm{s}$; (v) filaments merge at the gap center (i.e. the thermal spark is formed). These steps of formation were also reported in the work of Orriere [32, p.82]. The filaments were observed in a $200-\mu \mathrm{m}$ and 1-mm gap and their formation could also not be resolved with a 3-ns gate [32, p.82]. 
The molecular emission at low pressure $(58 \mathrm{mbar})$ and the atomic/continuum emission at high pressure (1 bar) show that the plasma composition varies significantly in the considered pressure range. The dependence of deposited energy as a function of the pressure is presented in Figure 7. The energy does not vary significantly in the studied pressure range, even though the spectra show a drastic change in the plasma $\left(\mathrm{N}^{+}\right.$emission and electron continuum versus $\mathrm{N}_{2}$ band emission). This indicates that there is no significant change in the total deposited energy at the transition from a non-thermal to a thermal spark. Thus, the energy appears to be deposited in a smaller volume for the thermal spark, which is consistent with the observation of Shcherbanev et al. [16].

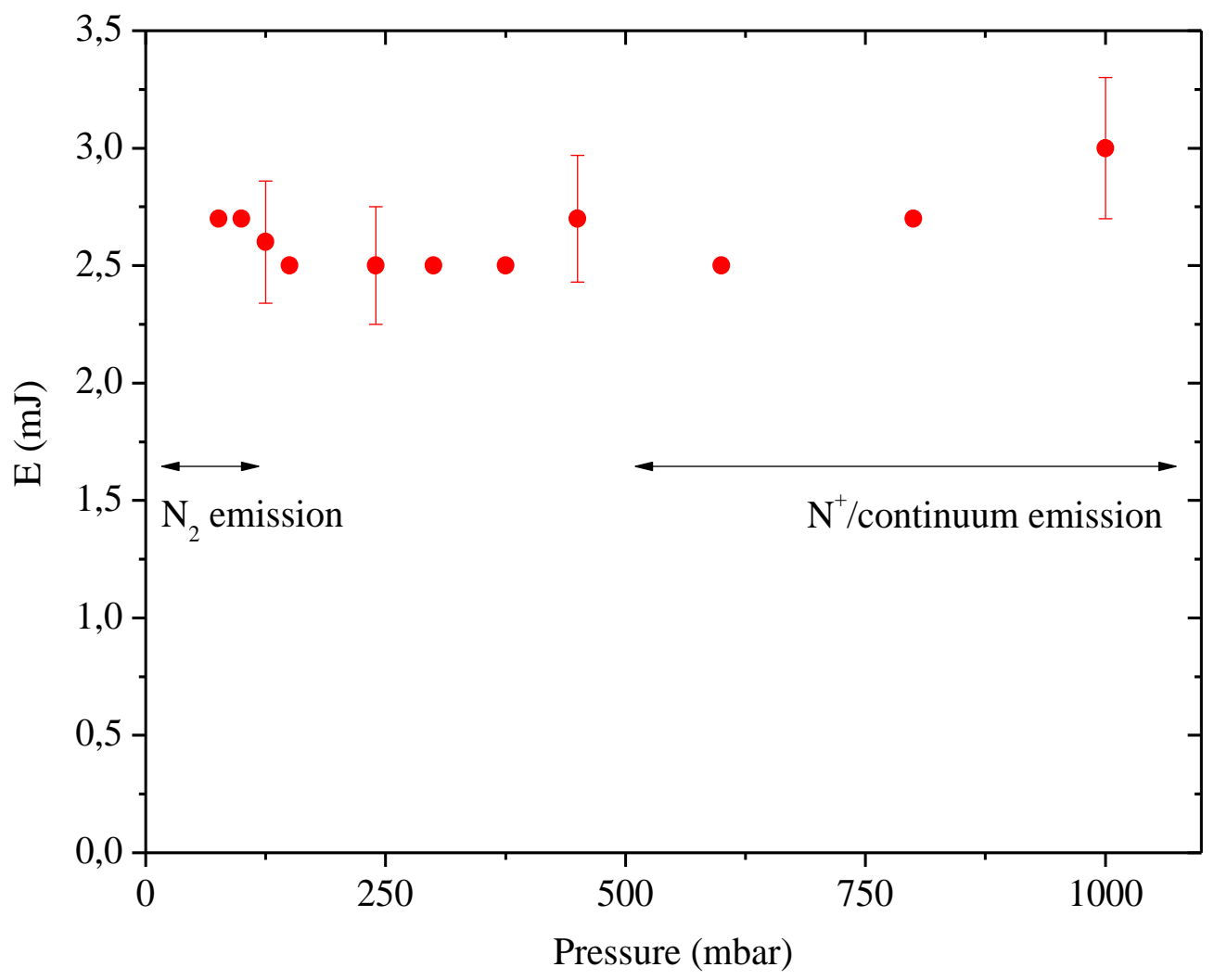

Figure 7 Deposited energy as a function of pressure for a gap of $0.9 \mathrm{~mm}$ between the electrodes (setup \#1). The ranges dominated by the emission of $\mathrm{N}_{2}$ or $\mathrm{N}^{+}$are shown by the arrows.

\section{Evolution of the electron number density and temperature at 1 atm}

In this section, the objective is to study the evolution of the electron number density, $n_{e}$, and of the electron temperature, $T_{e}$, in the post-discharge of the thermal spark at $1 \mathrm{~atm}$. The gap is $2 \mathrm{~mm}$, the anode is grounded, and the total deposited energy is equal to $2.5 \mathrm{~mJ}$ (Table 1). Single-shot images of the discharge development sequence for this case are shown in Figure 8. As described in Section 
3, the thermal spark develops according to the following sequence: (i) a homogeneous plasma is formed between the electrodes; (ii \& iii) the filaments appear at the cathode and the anode; (iv) the filaments propagate; and (v) merge at the end of the pulse. With setup \#1, the filaments had a constant length of $250 \mu \mathrm{m}$. With setup \#2, the filaments are twice as long $(500 \mu \mathrm{m})$. The filament length is therefore field-dependent. This aspect is not investigated in this paper.

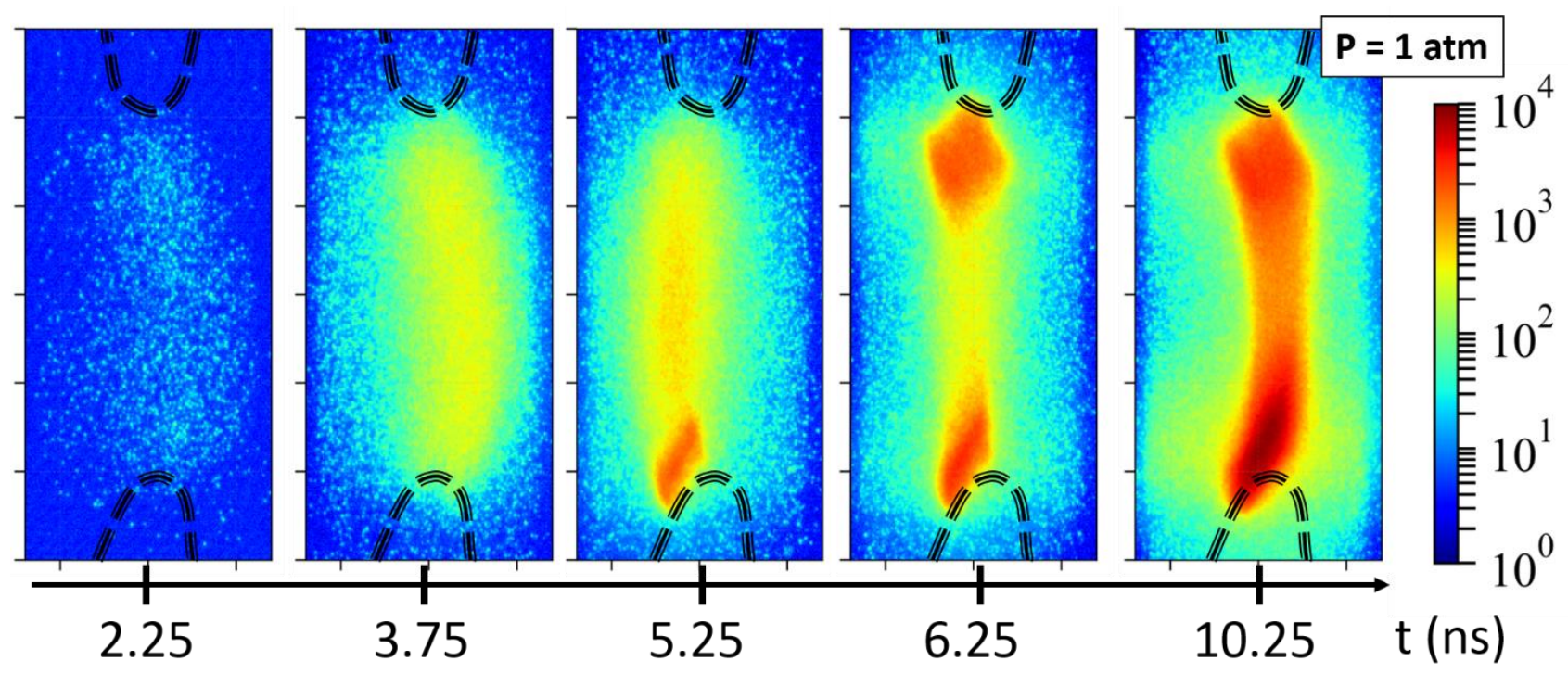

Figure 8 Phase-locked images with gates of 0.48 ns of a single nanosecond discharge applied across a 2mm gap (setup \#2). The images are single shot and are not Abel-inverted. The cathode is at the bottom.

The electron number density, $n_{e}$, is measured from the Stark broadening of $\mathrm{N}^{+}$lines with a temporal resolution of $0.5 \mathrm{~ns}$. The electron temperature, $T_{e}$, is obtained from the relative emission intensity of the three major groups of $\mathrm{N}^{+}$lines shown in Figure 9. The excited states of $\mathrm{N}^{+}$are assumed to follow a Saha-Boltzmann distribution in equilibrium with the free electrons, as considered in previous studies $[9,12,13,21]$. The following procedure is applied to obtain $n_{e}$. A spectrum is generated by an in-house extension of the SPECAIR code [33,34]. The lines are convolved with the instrumental broadening lineshape (fixed) and a Lorentzian (line-dependent). The width of the Lorentzian component and the electron temperature are varied until good agreement between the measured and simulated spectra is reached. The electron temperature is used to determine the Van der Waals and resonant broadening widths using the constants and formulas given in the Appendix. The Stark width is obtained by subtracting the Van der Waals and resonant widths from the total Lorentzian width of each line. The Stark width is then converted to $n_{e}$ using the work of Griem [35] (see Appendix). The Doppler broadening is negligible. A typical fit of the thermal spark emission spectrum is shown in Figure 9. The error on the electron number density and temperature 
measurements are $\pm 15 \%$ and $\pm 10 \%$, respectively, based on the maximal uncertainty of the fit and the uncertainty in the Van der Waals width (see Appendix). The values of $n_{e}$ and $T_{e}$ extracted from this spectrum are $1.4 \pm 0.2 \times 10^{19} \mathrm{~cm}^{-3}$ and $39,300 \pm 3900 \mathrm{~K}$.

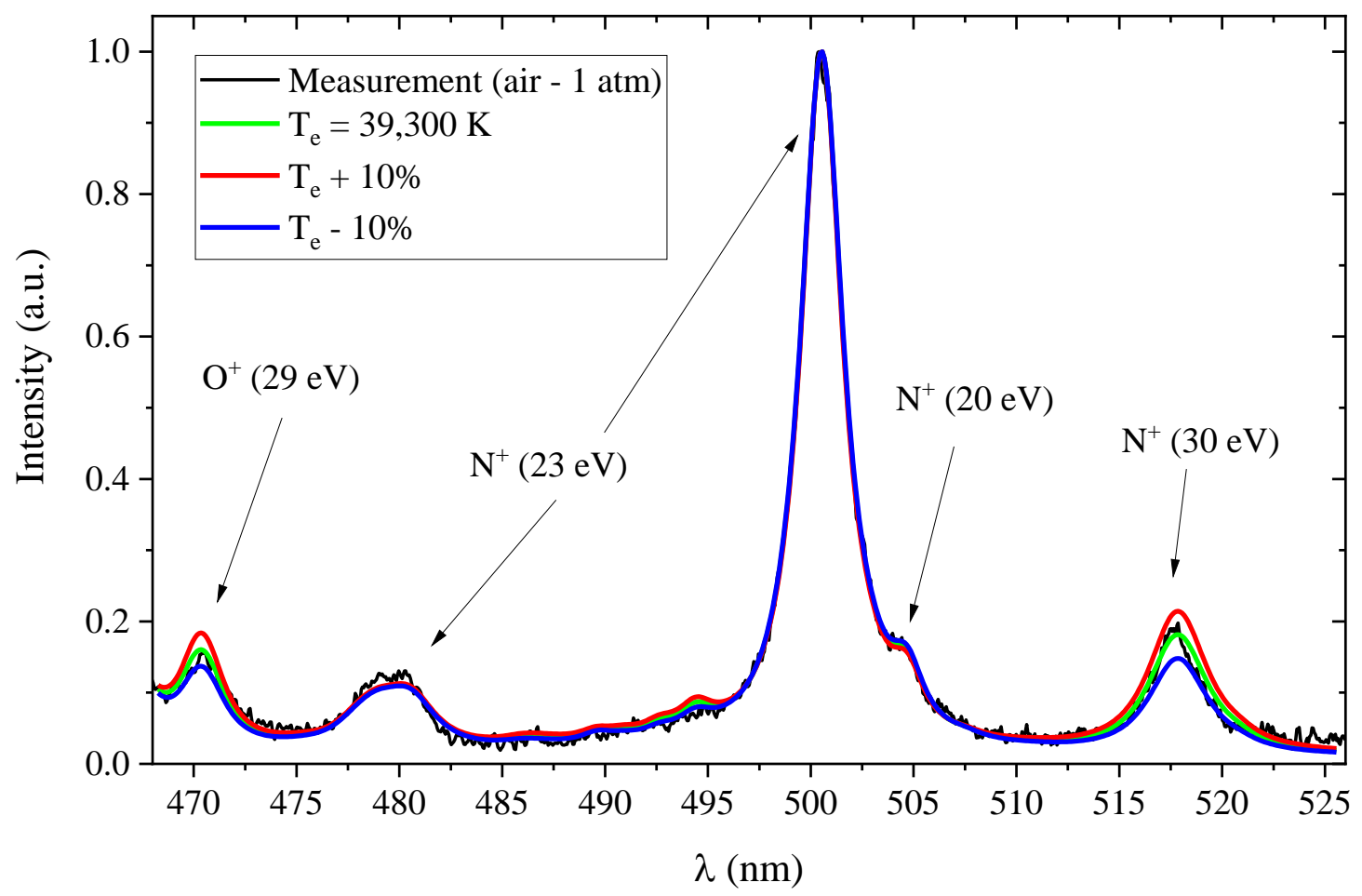

Figure 9 Measurements (black) and best fit (green) of the $N^{+}$and $\mathrm{O}^{+}$lines emitted by the discharge at $t=$ 19.5-20 ns in the setup \#2 (1 bar) near the cathode. Continuum emission (assumed to be linear) is subtracted. Best fit results: $n_{e}=1.4 \times 10^{19} \mathrm{~cm}^{-3}, T_{e}=39,300 \mathrm{~K}$. The experimental spectrum is obtained with 100 on-CCD accumulations. The energies of the dominant emitting levels, relative to the ground state of the corresponding ions, are indicated for reference.

The evolutions of $n_{e}$ and $T_{e}$ in the discharge afterglow are presented in Figure 10 and Figure 11. The entrance slit of the spectrometer is aligned parallel to the inter-electrode axis to perform measurements along the inter-electrode gap. Electron number densities are measured at four positions along the interelectrode gap, with the spatial binning indicated in Figure 10. From $t=6$ ns to $t=10 \mathrm{~ns}$, the emission of $\mathrm{N}^{+}$is visible only at the electrodes (i.e. only inside the filaments shown in Figure 8). The $\mathrm{N}^{+}$Stark broadening measurements show that, after $t=10 \mathrm{~ns}$, the electron number densities are approximately uniform across the entire interelectrode space. The electron number density approaches $4 \times 10^{19} \mathrm{~cm}^{-3}$ at $t=6 \mathrm{~ns}$ for $T_{e}=45,000 \mathrm{~K}$. The total gas density at $300 \mathrm{~K}, 1 \mathrm{~atm}$, is $2.5 \times 10^{19} \mathrm{~cm}^{-3}$. According to Sher et al. [Figure 2, 36], after isochoric heating to temperatures around $45,000 \mathrm{~K}$ the main species are $\mathrm{N}^{+}, \mathrm{O}^{+}$, and electrons (the $\mathrm{N}^{++}$mole fraction is below $8 \%$ at $45,000 \mathrm{~K}$ and the $\mathrm{O}^{++}$mole fraction is less than $1 \%$ ). Therefore, the total gas density 
at the end of the pulse should be around four times the initial density because, for each initial diatomic molecule, two atoms are formed, which in turn transform into two atomic ions and electrons. Thus, full ionization at the end of the pulse would correspond to about $5 \times 10^{19}$ heavy particles $/ \mathrm{cm}^{3}$ and the same density for free electrons, assuming each atom is ionized once. Therefore, the measured electron number density of about $4 \times 10^{19} \mathrm{~cm}^{-3}$ is consistent with full ionization and dissociation at the end of the pulse. The spatial distribution of the electron temperature is also found to be uniform across the gap. The temporal evolution of the spatially averaged $T_{e}$ is shown in Figure 11. The maximal electron temperature right after the discharge is $48,000 \pm 5,000 \mathrm{~K}$, then decays to about 30,000 K within $90 \mathrm{~ns}$.

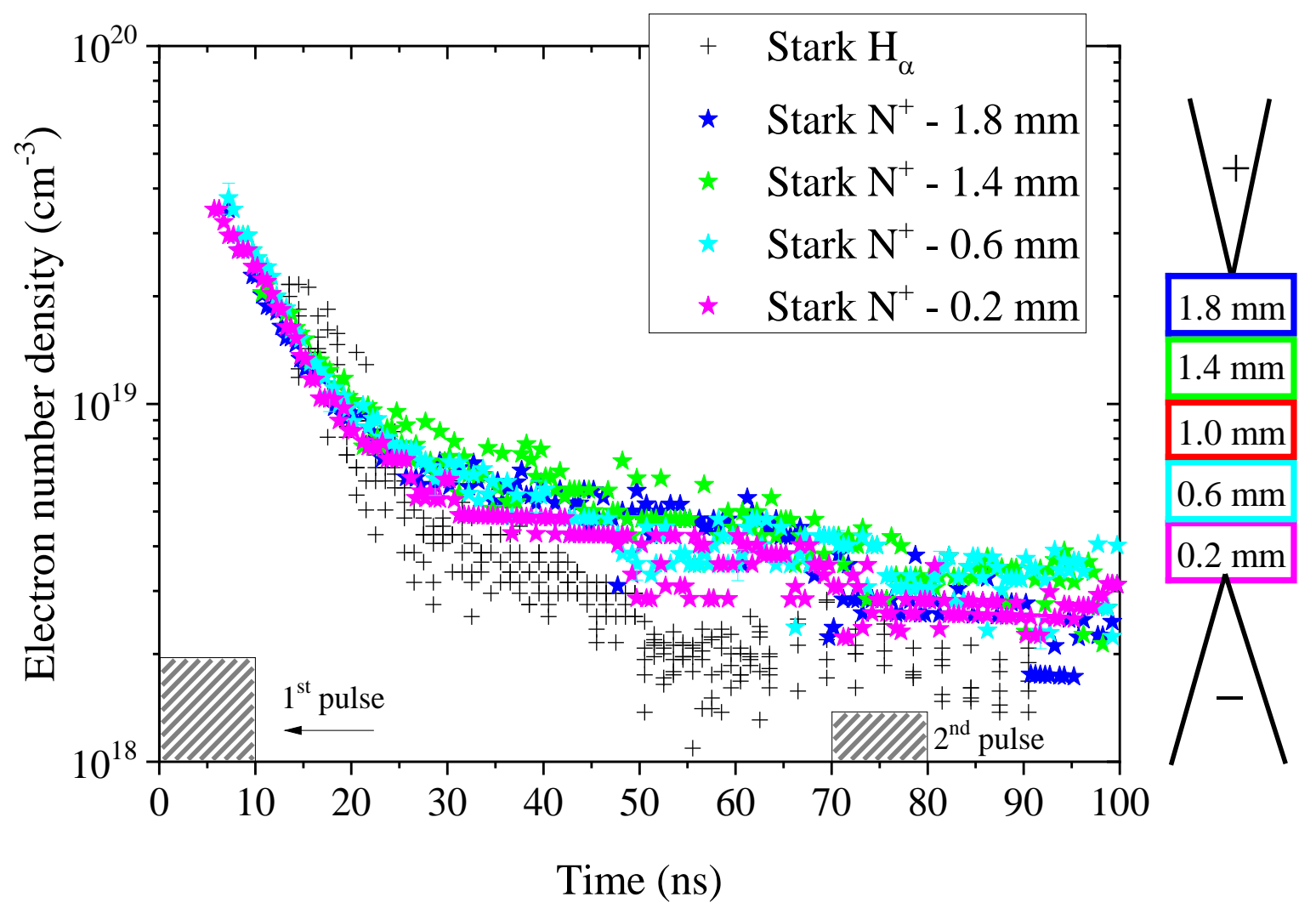

Figure 10 Temporal evolution of the measured electron number density at various positions along the 2mm interelectrode gap ( setup \#2), determined from the Stark width of $N^{+}$lines (colored stars) and $H_{\alpha}$ (black crosses). The distance from the cathode is shown in $\mathrm{mm}$. The nanosecond pulses are represented by the dashed areas. 


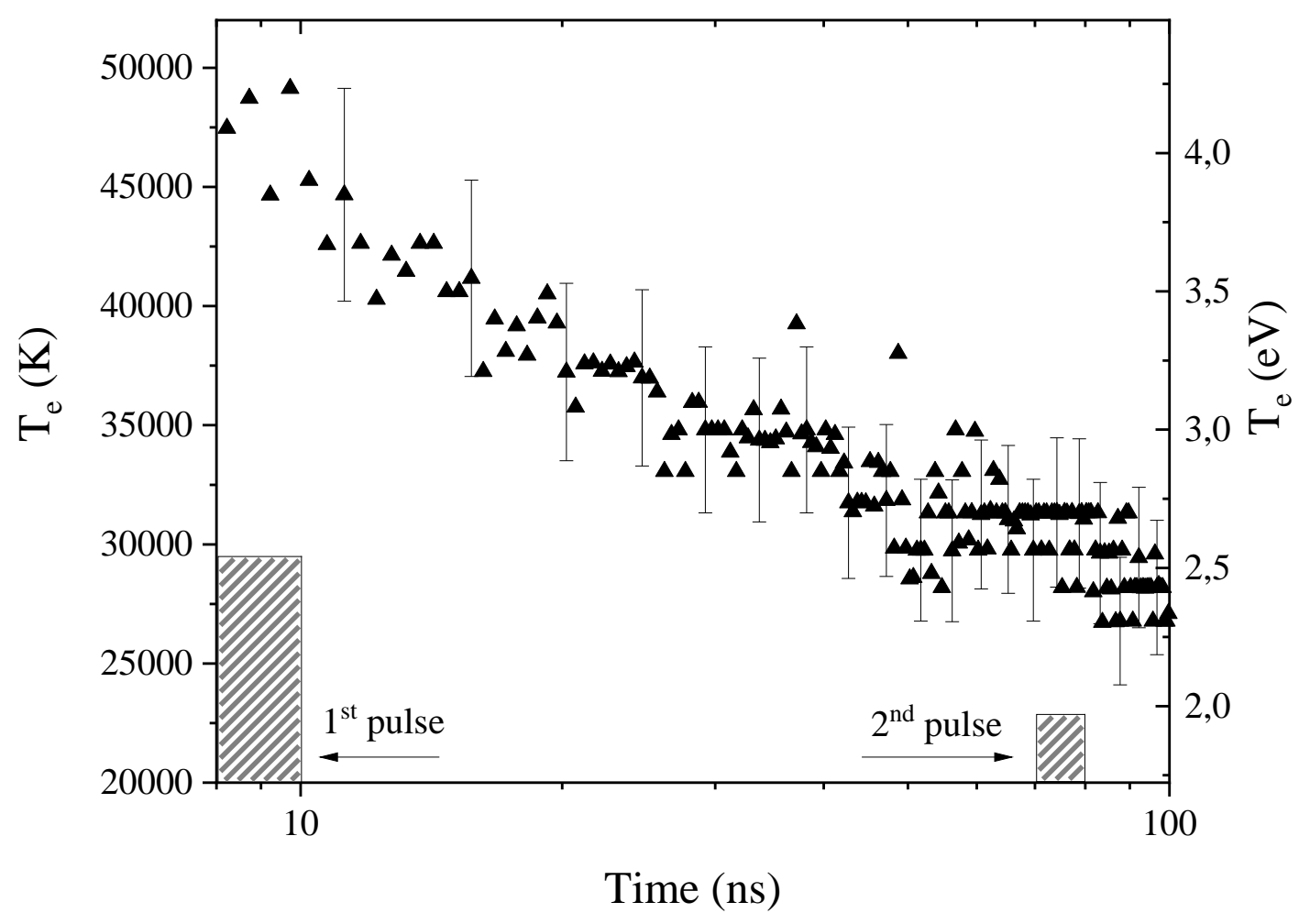

Figure 11 Decay of the measured electron temperature. The measurements are spatially averaged along the gap.

An additional measurement of the electron number density is obtained from the Stark broadening of $\mathrm{H}_{\alpha}$ (recall that for these experiments with setup \#2, $1.6 \%$ of hydrogen is added to air). Figure 12 shows two measurements and two fits of the Stark-broadened $\mathrm{H}_{\alpha}$ line at $t=60$ and $1000 \mathrm{~ns}$. The instrumental broadening width is always less than the measured linewidth over this entire time interval, although it becomes comparable with the Stark width at $1000 \mathrm{~ns}$. We apply the same fitting procedure as for $\mathrm{N}^{+}$: a Lorentzian convolved with the instrumental broadening lineshape is fitted to the experimental spectrum. The electron number density is obtained after subtraction of the Van der Waals and resonant broadening widths from the total Lorentzian width. The Doppler width is still negligible. The electron number densities inferred from the Stark broadening of the $\mathrm{N}^{+}$and $\mathrm{H}_{\alpha}$ lines are compared in Figure 10. The data from $\mathrm{H}_{\alpha}$ broadening are also spatially resolved, and we found a homogeneous distribution of the electrons along the gap. This homogeneity was also reported in a similar discharge [9]. The results obtained with the $\mathrm{H}_{\alpha}$ line are only shown for $t>12 \mathrm{~ns}$, i.e. after the electron number density has decayed to $2 \times 10^{19} \mathrm{~cm}^{-3}$. This is because the Stark-broadened $\mathrm{H}_{\alpha}$ line is much wider than the spectral measurement window at electron number densities higher than $2 \times 10^{19} \mathrm{~cm}^{-3}$. For example, according to Ref. [37] and Eq. 
13, an electron number density of $10^{19} \mathrm{~cm}^{-3}$ leads to an $\mathrm{H}_{\alpha}$ FWHM of $25 \mathrm{~nm}$. The results obtained from the Stark-broadened $\mathrm{H}_{\alpha}$ line after $12 \mathrm{~ns}$ are in good agreement with those of the $\mathrm{N}^{+}$line given that the experimental [38] and theoretical [35] $\mathrm{N}^{+}$Stark coefficients can differ by up to a factor of two in the literature. Spatially averaged measurements of $n_{e}$ from $\mathrm{H}_{\alpha}$ broadening are shown in

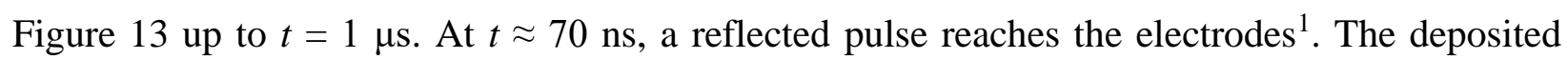
energy is lower than for the first pulse $(\approx 0.1 \mathrm{~mJ}$ versus $2.5 \mathrm{~mJ})$ but is sufficient to induce a small amount of additional ionization. For $t>100 \mathrm{~ns}$, the temperature is not known. The uncertainty on the Van der Waals calculation is therefore increased. The lower limit of the error bars in Figure 13 indicates the values that would be obtained if a constant value of $T_{\text {gas }}=28,000 \mathrm{~K}$ were chosen in the Van der Waals width calculation. Our measurements are compared in Figure 13 with those reported for other thermal sparks in the literature $[9,12,13]$. They are found to agree in first approximation, and a detailed comparison is given in Section 5.
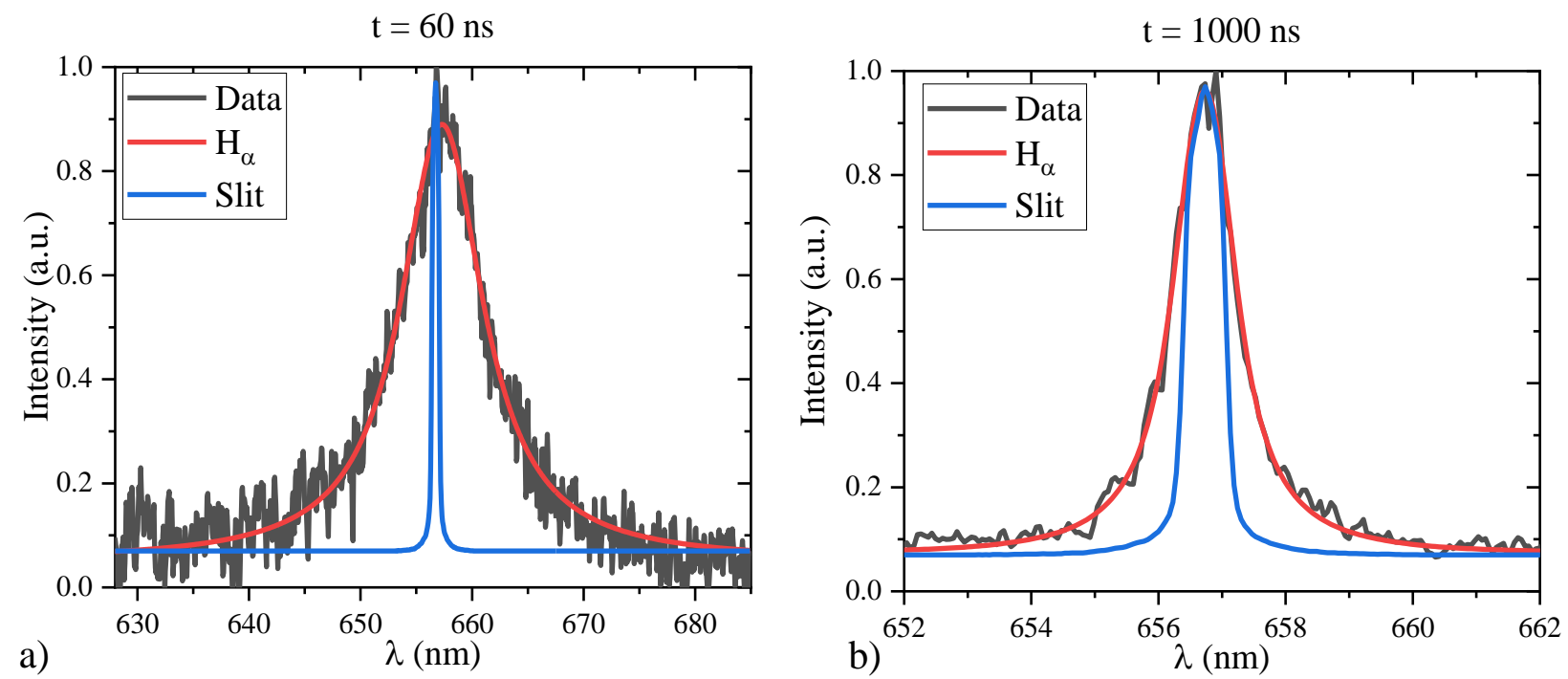

Figure 12 Spatially averaged emission of the $H_{\alpha}$ line in black recorded at (a) $t=60 \mathrm{~ns}$ and (b) $t=1000 \mathrm{~ns}$. The instrumental broadening lineshape is displayed in blue and the fit including Stark broadening in red. The line at $t=1000 \mathrm{~ns}$ corresponds to the narrowest $H_{\alpha}$ line measured in this work (Stark FWHM of 0.81 $n m$ ).

\footnotetext{
${ }^{1}$ This timing corresponds to the speed of propagation of the electrical signal, $20 \mathrm{~cm} / \mathrm{ns}$, and the length of the cables, $7 \mathrm{~m}$. The same phenomenon was seen in Ref. [71].
} 


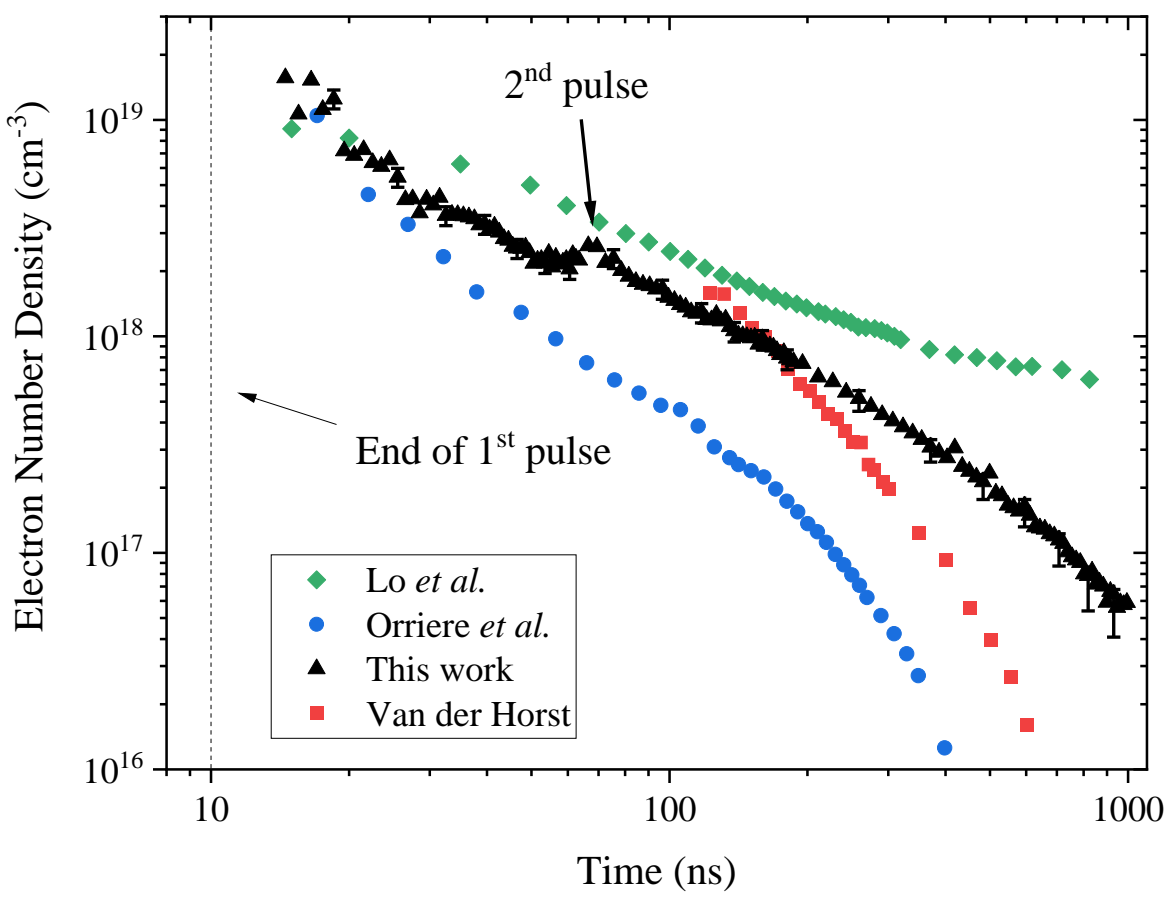

Figure 13 Decay of the electron number density, measured from the Stark broadening of $H_{\alpha}$ (black triangles). The increase of $n_{e}$ at $t \approx 70$ ns is caused by the reflected pulse. The measurements performed by van der Horst et al. in $\mathrm{N}_{2}+0.9 \% \mathrm{H}_{2} \mathrm{O}$ [12] (red squares), Orrière et al. in air [13] (blue circles), and Lo et al. in air [9] (green diamonds) are shown for comparison.

Van der Horst et al. [12] measured the gas temperature in the first few nanoseconds of a similar discharge by fitting the rotational structures of $\mathrm{N}_{2}(\mathrm{C})$, and $1 \mu$ s after the discharge by Rayleigh scattering. The authors also measured $n_{e}$, shown in Figure 13, and estimated the dominant electron loss process to be three-body recombination via Reac. 1 .

$$
N^{+}+e^{-}+e^{-} \rightarrow N+e^{-}
$$

Reac. 1

Van der Horst et al. [12] assumed the rate coefficient of Reac. 1 to be $k_{3, \text { rec }}=7 \times 10^{-20}\left(300 / T_{e}\right)^{4.5} \mathrm{~cm}^{6} / \mathrm{s}$ (taken from [39]), and deduced from a fit of the $n_{e}$ decay that the electron temperature (not measured in their work) should be around $2.3 \mathrm{eV}$, a value they deemed too high for a recombining plasma. Instead, they concluded that additional electrons were produced via Penning ionization.

If we apply the approach of van der Horst et al. [12], we also find that our experimental decay rate of electrons is much slower than the rate [39] of Reac. 1. In our conditions, a fit of the $n_{e}$ decay 
within $10-20$ ns would require a temperature of 70,000 K, which is almost twice the measured value. In this section, we propose an explanation for our observed electron decay.

The importance of volume expansion in the decay of $n_{e}$ was shown in Ref. [9]. The speed of sound is equal to $c_{s}=\sqrt{\gamma R T_{\text {gas }} / M}$ where $\gamma=1.25$ is the ratio of specific heats [40], $R$ the perfect gas constant, $T_{\text {gas }}$ the gas temperature, and $M$ the molar mass. In a gas composed of electrons (50\%), nitrogen ions (40\%), and oxygen ions (10\%), the molar mass is $7.2 \mathrm{~g} \cdot \mathrm{mol}^{-1}$, and the speed of sound ranges between 6500 and $7500 \mathrm{~m} \cdot \mathrm{s}^{-1}$ for $T_{e}$ in the range 30,000 - 50,000 K. Thus, the hydrodynamic timescale for a plasma with a radius $r=100 \mu \mathrm{m}$ is $r / c_{s} \approx 14 \mathrm{~ns}$. Therefore, the pressure is homogeneous in the plasma channel and the volume expansion already begins by the end of the pulse. We therefore expect the volume expansion to induce a decrease in the electron number density. Lo et al. [9] showed the decay of $n_{e}$, reproduced in Figure 13, as being due to an isentropic volume expansion up to $t=150 \mathrm{~ns}$. The relation between $T_{e}$ and $n_{e}$ during an isentropic expansion is given by Eq. 1 [9].

$$
\frac{n_{e}^{\gamma-1}}{T_{e}}=c s t
$$

Figure 14 shows our measurements of $n_{e}$ versus $T_{e}$, fitted by $T_{e}=a\left(n_{e}\right)^{b}$. The fit gives $\gamma=1.24$, which is close to:

- $1.2-1.3$, the value measured in Ref. [9], and

- 1.2 - 1.25, the value calculated in Ref. [40] for air at 100 bar between 30,000 and 50,000 K. 


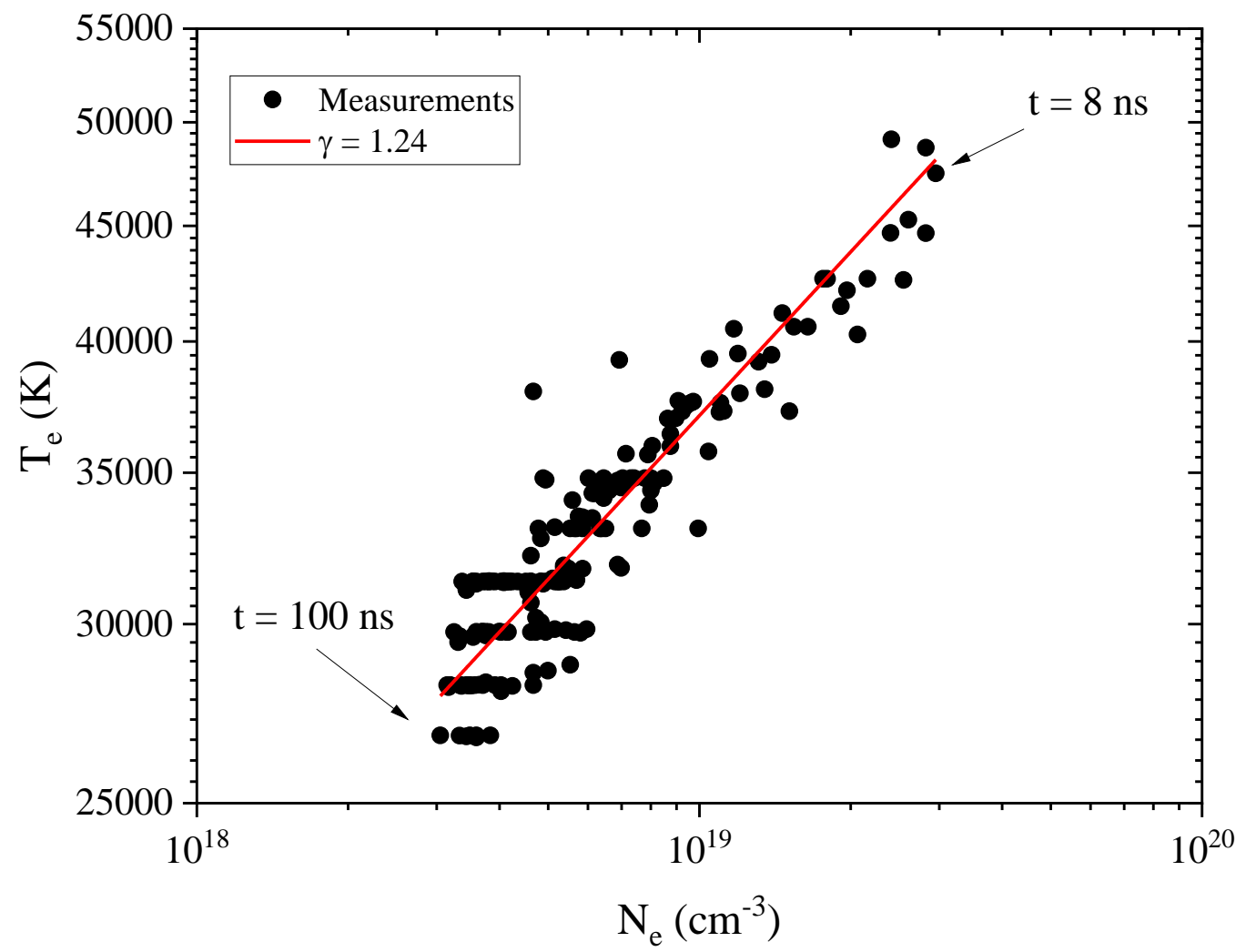

Figure $14 T_{e}$ versus $n_{e}$ from 8 to $100 \mathrm{~ns}$ in a logarithm scale. Spatially averaged values are displayed. The measurements are fitted by a law in $T_{e}=a \times n_{e}^{0.24}$ which corresponds to $\gamma=1.24 \pm 0.01 \mathrm{in} \mathrm{Eq.} 1$.

It is interesting to determine when heat conduction starts cooling the plasma. The characteristic time of cooling by heat conduction can be estimated as $\tau_{c o n d}=\rho c_{p} r^{2} \lambda$ [26, p. 199]. The thermophysical quantities, taken at 133 bar and 20,000 $\mathrm{K}$ (the average temperature of the plasma and of ambient air), are $\rho=0.9 \mathrm{~kg} \cdot \mathrm{m}^{-3}, c_{p}=10 \mathrm{~kJ} \cdot \mathrm{kg}^{-1} \cdot \mathrm{K}^{-1}$ and $\lambda=7.8 \mathrm{~W} \cdot \mathrm{m}^{-1} \cdot \mathrm{K}^{-1}$ [41]. We obtain $\tau_{\text {cond }}=12 \mu \mathrm{s}$ and therefore losses by thermal conduction are negligible over the time scale of our measurements. Regarding radiation losses, it was shown for a $15-\mathrm{mJ}$ laser spark that radiation dissipates $22 \%$ of the deposited energy [42]. A lower limit for the characteristic time of radiation cooling, $\tau_{\text {rad }}$, can be obtained by assuming the plasma to be a blackbody. At $T=T_{e}=45,000 \mathrm{~K}$ and with $\sigma$, the Stefan constant, we calculate $\tau_{\text {rad }}=\rho c_{p} r / 2 \sigma T^{3} \approx 60 \mathrm{~ns}$. As can be clearly seen in Figure 6 , the radiation is far below the blackbody emission and therefore $\tau_{\text {rad }}$ should be much longer than $60 \mathrm{~ns}$. Therefore, radiation losses are not expected to be the primary mechanism of plasma cooling from 0 to $100 \mathrm{~ns}$. However, they could be taken into account to refine the spark model, see for instance Ref. [43]. 
Regarding state-to-state ionization, state-to-state recombination, and volume expansion, the rate of electron decay can be modeled with Eq. 2:

$$
\begin{aligned}
\frac{d n_{e}}{d t}=\left(k_{i, N\left({ }^{4} S\right)}\right. & \left.n_{N\left({ }^{4} S\right)}+k_{i, N\left({ }^{2} D\right)} n_{N\left({ }^{2} D\right)}+k_{i, N\left({ }^{2} P\right)} n_{N\left({ }^{2} P\right)}+\cdots\right) n_{e} \\
& -\left(k_{r e c, N\left({ }^{4} S\right)}+k_{r e c, N\left({ }^{2} D\right)}+k_{r e c, N\left({ }^{2} P\right)}+\cdots\right) n_{N^{+}} n_{e}^{2}-\frac{d V}{d t} \frac{1}{V} n_{e}
\end{aligned}
$$

where $k_{i, N(X)}$ is the ionization rate coefficient of state $\mathrm{X}, k_{\operatorname{rec}, N(X)}$ the recombination rate coefficient of $\mathrm{N}^{+}$in state $\mathrm{X}, n_{N^{+}}$the $\mathrm{N}^{+}$density, and $V$ the plasma volume. We already showed that the last term on the right-hand side of Eq. 2 is driving the decrease of $n_{e}$ in Figure 14. We now demonstrate with a state-to-state model that ionization compensates the chemical recombination of electrons during the expansion. Assuming isochoric dissociation during the discharge, the total heavy particle density at $t=8 \mathrm{~ns}$ is $5 \times 10^{19} \mathrm{~cm}^{-3}$. From $t=8 \mathrm{~ns}$ to $t=12 \mathrm{~ns}, T_{e}$ decreases from 48,000 to $40,000 \mathrm{~K}$. In an isentropic expansion, the quantity $T_{e} V^{\gamma-1}$ is conserved, implying an increase of the plasma volume by a factor of 2 . Thus, the total heavy particle density is $2.5 \times 10^{19}$ $\mathrm{cm}^{-3}$ at $t=12 \mathrm{~ns}$. We assume that the dominant ion is $\mathrm{N}^{+}$and that the remaining heavy particles are atomic nitrogen. Thus, at $t=12 \mathrm{~ns}, T_{e} \approx 40,000 \mathrm{~K}$ (Figure 11), $n_{e} \approx n_{N_{+}} \approx 2 \times 10^{19} \mathrm{~cm}^{-3}$ (Figure 10 ), and $n_{N} \approx 0.5 \times 10^{19} \mathrm{~cm}^{-3}$. The populations of the excited states are computed using the partition functions of NIST [31], assuming a Boltzmann distribution. The ground state number density, $n_{N\left({ }^{4} S\right)}$, represents $10 \%$ of the atomic nitrogen number density, whereas the metastable states, $n_{N\left({ }^{2} D\right)}$ and $n_{N\left({ }^{2} P\right)}$, represent $12 \%$ and $5 \%$, respectively. The remaining $73 \%$ occupy higher excited states. Using the rate coefficients of Ref. [44] and detailed balancing, we find that the ionization rate of $\mathrm{N}\left({ }^{4} \mathrm{~S}\right)$ is comparable with the recombination rate of $\mathrm{N}^{+}$into $\mathrm{N}\left({ }^{4} \mathrm{~S}\right)\left(k_{i, g s} n_{N\left({ }^{4} S\right)} n_{e} \sim 10^{27} \mathrm{~cm}^{-}\right.$ ${ }^{3} \mathrm{~s}^{-1}$ versus $\left.k_{\text {rec,gs }} n_{N^{+}} n_{e}^{2} \sim 10^{27} \mathrm{~cm}^{-3} \mathrm{~s}^{-1}\right)$. The same conclusion is obtained for metastable $\left(\sim 10^{27}\right.$ $\left.-10^{28} \mathrm{~cm}^{-3} \mathrm{~s}^{-1}\right)$ and higher excited states up to $E=11.8 \mathrm{eV}\left(\sim 10^{28}-10^{29} \mathrm{~cm}^{-3} \mathrm{~s}^{-1}\right)$. We repeated this calculation up to the last point for which we measured $T_{e}$ and found that ionization balances recombination until $t=100 \mathrm{~ns}$. Therefore, up to at least $\mathrm{t}=100 \mathrm{~ns}$, the thermal spark is in chemical equilibrium.

At longer timescales $(t>1 \mu \mathrm{s})$, hydrodynamic effects lead to the formation of a torus and the mixing of the plasma column with fresh gas [45-49]. In the numerical study of Ref. [29], a dimensionless number, defined in Eq. 3, was introduced to predict the discharge conditions for which recirculation occurs. 


$$
\Pi_{T r}=\frac{E_{u h}}{p_{0} S d}
$$

Eq. 3

The $\Pi_{\operatorname{Tr}}$ number depends on $E_{u h}$ the energy deposited into fast gas heating, $p_{0}$ the initial pressure, $S$ the plasma cross-section, and $d$ the interelectrode gap distance. This number can be seen as the ratio of the energy deposited into fast gas heating and the energy already contained in the discharge volume prior to breakdown. As shown in Ref. [29], a torus forms when $\Pi_{T r}>60-80$. In our case, $E_{u h}=2.5 \mathrm{~mJ}, p_{0}=10^{5} \mathrm{~Pa}, S=0.025 \mathrm{~mm}^{2}$ and $d=2 \mathrm{~mm}$, which gives $\Pi_{T r}=500$. This indicates that a torus will be formed and therefore that fresh gases recirculate into the plasma column. However, this recirculation does not occur before $1 \mu \mathrm{s}$, as can be clearly seen from Figure 5 of Ref. [45], obtained for discharge under similar conditions. Therefore, recirculation does not affect the decay of $n_{e}$ shown in Figure 13.

\section{Comparison with other nanosecond thermal sparks in the literature}

In this section, we compare and discuss the electron density decay curves presented in Figure 13. These results were obtained in ambient air or $\mathrm{N}_{2}$, using nanosecond discharges with fairly similar characteristics, as reported in Table 2 . In all cases, nearly fully ionized plasmas were produced.

As can be seen in Figure 13, the electron density curves all start with a nearly fully ionized plasma at the end of the pulse, and then follow the same evolution after the pulse. It is important to note that the initial discharge radii vary from $20 \mu \mathrm{m}$ (Orrière et al.) to around 100-120 $\mu \mathrm{m}$ (van der Horst et al., Lo et al., and present work). A small radius (30 $\mu \mathrm{m}$ at $t=15 \mathrm{~ns}$ ) was also reported by Albrecht et al. [21]. The reasons explaining these different $\operatorname{radii}^{2}$ are not known. The small discharge radius reported by Orrière et al. cannot be explained by their small gap (200 $\mu \mathrm{m})$, because Orrière obtained a similar discharge radius with a 1-mm gap [32]. Nevertheless, the rate of volume expansion is related to the hydrodynamic timescale, which is proportional to the initial radius of the discharge channel, and Figure 13 confirms that electrons recombine faster when the initial discharge radius is smaller. For a more quantitative comparison, one would have to consider other parameters, such as the energy per unit volume, and the effect of a spherical expansion (in short gaps) compared to cylindrical one (in long gaps).

\footnotetext{
${ }^{2}$ The discharge radius was measured by OES in Refs. [9,12,13,21] and this work. In Ref. [9], the radius measured by OES corresponded to the radius of the electron distribution.
} 
Table 2 Parameters of the thermal sparks studied by van der Horst et al. [12], Orriere et al. [13], Lo et al. [9], and in the present work. The voltage pulse of Lo et al. is 20 ns in duration, whereas the current lasts for hundreds of nanoseconds.

\begin{tabular}{|c|c|c|c|c|c|c|c|c|c|c|}
\hline Ref. & Gas & $\begin{array}{c}\mathbf{T} \\
(\mathbf{K})\end{array}$ & $\begin{array}{c}\text { Gap } \\
(\mathbf{m m})\end{array}$ & $\begin{array}{l}V_{\max } \\
(\mathrm{kV})\end{array}$ & $\begin{array}{c}\text { PRF } \\
(\mathbf{k H z})\end{array}$ & $\begin{array}{c}\text { Pulse } \\
\text { length } \\
\text { (ns) }\end{array}$ & $\begin{array}{c}\text { Initial } \\
\text { radius } \\
(\mu \mathrm{m})\end{array}$ & $\begin{array}{c}\text { Energy } \\
(\mathrm{mJ})\end{array}$ & $\begin{array}{l}n_{e, \max } \\
\left(\mathbf{c m}^{-3}\right)\end{array}$ & $\begin{array}{c}T_{e, \max } \\
(\mathbf{K})\end{array}$ \\
\hline $\begin{array}{c}\text { Orrière } \\
\text { et al. } \\
\text { [13] }\end{array}$ & $\begin{array}{c}\text { Air } \\
(1 \mathrm{~atm})\end{array}$ & 370 & 0.2 & 2.5 & 8 & 30 & $\begin{array}{c}20 \pm 4 \\
(t<15 \mathrm{~ns})\end{array}$ & 0.1 & $\begin{array}{c}1 \times 10^{19} \\
(t=12 \mathrm{~ns})\end{array}$ & 70,000 \\
\hline $\begin{array}{l}\text { Van der } \\
\text { Horst } e t \\
\text { al. [12] }\end{array}$ & $\begin{array}{c}\mathrm{N}_{2} \\
\mathrm{~N}_{2}+0.9 \% \\
\mathrm{H}_{2} \mathrm{O} \\
(1 \mathrm{~atm})\end{array}$ & 350 & 2 & 9 & 1 & 170 & $\sim 100$ & 1.0 & $\begin{array}{c}4 \times 10^{18} \\
(t=100 \mathrm{~ns})\end{array}$ & - \\
\hline $\begin{array}{c}\text { Lo et al. } \\
\text { [9] }\end{array}$ & $\begin{array}{c}\text { Air } \\
(1 \mathrm{~atm})\end{array}$ & 300 & 3 & 30 & 0.01 & 20 & $\begin{array}{c}120 \\
(t=15 \mathrm{~ns})\end{array}$ & $>55$ & $\begin{array}{c}9 \times 10^{18} \\
(t=15 \mathrm{~ns})\end{array}$ & 44,000 \\
\hline $\begin{array}{c}\text { Present } \\
\text { work }\end{array}$ & $\begin{array}{c}\text { Air }+ \\
1.6 \% \mathrm{H}_{2} \\
(1 \mathrm{~atm})\end{array}$ & 300 & 2 & 5.5 & 0.05 & 10 & $\begin{array}{c}\sim 100 \\
(t=10 \mathrm{~ns})\end{array}$ & 2.5 & $\begin{array}{c}4 \times 10^{19} \\
(t=8 \mathrm{~ns})\end{array}$ & 45,000 \\
\hline
\end{tabular}

As shown in Figure 13, the electron density decay measured by Orrière et al. [13] and the one measured in the present work follow approximately the same trend. The slightly faster decay reported in Ref. [13] could be due to their smaller initial plasma radius, or to the fact that the volume expansion of their plasma is spherical (versus cylindrical in our case), and to the presence in our case of a second pulse (at $t \approx 70 \mathrm{~ns}$ ). Like van der Horst et al., Orriere et al. [13] fitted the electron decay with Reac. 1 only (i.e. neglecting the ionization of $\mathrm{N}$ and the plasma expansion). However, using the cross-sections of Wang et al. [50], it was also shown in Ref. [13] that the characteristic ionization times of $\mathrm{N}\left({ }^{2} \mathrm{P}\right)$ and $\mathrm{N}\left({ }^{2} \mathrm{D}\right)$ were comparable with the experimental recombination time for $t<100 \mathrm{~ns}$. We obtained the same conclusions using the ionization rate coefficients derived by Ciccarino et al. [44]. Furthermore, in his thesis [32, Fig. 74], Orriere reported the discharge radius evolution, measured by OES. Between $t=10 \mathrm{~ns}$ and $t=100 \mathrm{~ns}$, the discharge volume increased by a factor $3-5$ while $n_{e}$ was divided by 25 . Based on these two observations, we conclude that Reac. 1 is not sufficient to model $n_{e}$ decay for $\mathrm{t}<100 \mathrm{~ns}$, and that ionization (reverse of Reac. 1) and volume expansion should also be considered. 
As detailed before, van der Horst et al. [12] calculated that if only Reac. 1 is considered, a temperature of $2.3 \mathrm{eV}=27,000 \mathrm{~K}$ would be necessary to explain the relatively slow decay of $n_{e}$. Van der Horst et al. considered this value to be unrealistically high for a nonequilibrium plasma. However, in light of the present work and of the measurements reported in Table 2, it appears likely that the electron temperature could indeed reach such high values, and perhaps even higher. For $t<100 \mathrm{~ns}, n_{e}$ was not measured by van der Horst et al. Given the similarities between this discharge and the others in Table 2, it is expected that $n_{e}$ reached $10^{19} \mathrm{~cm}^{-3}$ during the 100 -ns pulse of Ref. [12].

In Ref. [9], Lo et al. showed that the decay of $n_{e}$ in the afterglow of their thermal spark was due to an isentropic expansion. Their 2D-resolved measurements of $n_{e}$ clearly demonstrated an expansion of the plasma channel, beginning at $t=15 \mathrm{~ns}$. They also found a homogeneous electron density distribution along the interelectrode gap, as in our experiments. However, $T_{e}$ was higher at the electrodes than in the middle of the gap and the $T_{e}$ values measured in Ref. [9] are close to those reported in this work. Chemical equilibrium is therefore expected at least up to $t=100 \mathrm{~ns}$. For $t>$ $300 \mathrm{~ns}$, the electron decay is slower than in the other references, see Figure 13, possibly because the current lasted for more than $500 \mathrm{~ns}$ in their experiment. Also, the $n_{e}$ inferred from the Stark broadened $\mathrm{N}^{+}$lines might be somewhat overestimated at $t>300 \mathrm{~ns}$ because Van der Waals broadening was not taken into account in their lineshape analysis (see Table 9 in the appendix).

\section{Comparison with spark discharges used for combustion ignition}

The transition in a few nanoseconds from a $\mathrm{N}_{2}$-emission dominated spectrum to a continuum/ $\mathrm{N}^{+}$dominated spectrum is also observed in discharges of longer durations, in particular the discharges used for combustion ignition in car engines. The latter ones are typically a few milliseconds long and evolve in three phases, as described by Maly et al. [51]: the "breakdown" phase $(\approx 10 \mathrm{~ns})$, the "arc" phase $(\approx 1-10 \mu \mathrm{s})$ and the "glow" phase $(\approx 1 \mathrm{~ms})$. Albrecht et al. [21] recorded the emission of $\mathrm{N}^{+}$lines already at $7 \mathrm{~ns}$ in these discharges, and showed that it became dominant after $15 \mathrm{~ns}$. The electron temperatures and electron number densities measured by Albrecht et al. [21] are similar to those studied here and in other references [9,12-17,52]. The comparison of $T_{e}$ and $n_{e}$ measured by Albrecht et al. and in this work is shown in Figure 15. The electron number density measurements agree remarkably, within better than a factor of 1.5. The temperatures profiles are also comparable, albeit about $30 \%$ higher in Ref. [21]. It is difficult to determine the reason for this difference (potentially due to an overlap of $\mathrm{O}^{+}$and $\mathrm{N}^{+}$lines, or to inaccurate Einstein 
coefficients) because Albrecht et al. do not give the details of their measurements and analysis. The energy deposited during (i) the "breakdown" phase of millisecond discharges and (ii) the nanosecond discharges is also similar and equal to a few $\mathrm{mJ}$ [21,53]. The early phase of longer sparks used for combustion ignition has therefore the same characteristics as the nanosecond thermal spark reported here.
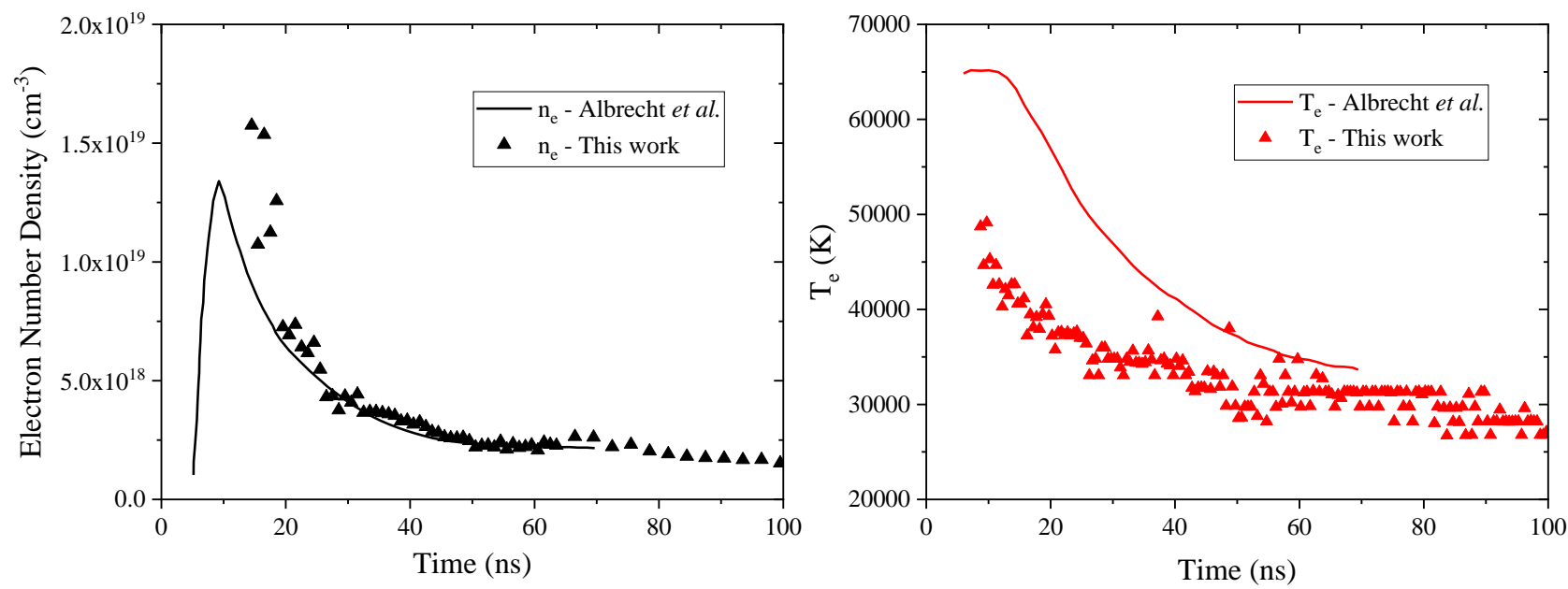

Figure 15 Comparison between the measurements of Albrecht et al. [21] (full lines) and this work (triangles). The data of this work corresponds to the measurements presented in Figure 13 and Figure 11.

\section{Conclusions}

This paper shows that, under certain conditions, nanosecond discharges in air can produce a fully ionized plasma $\left(n_{e} \sim 10^{19} \mathrm{~cm}^{-3}\right)$, with intense $\mathrm{N}^{+}$lines and continuum emission in the interelectrode gap. We call this regime the thermal spark, to distinguish it from the previously observed corona, glow, and non-thermal spark regimes observed by Pai et al. [1]. Through fast imaging, the following steps of formation of the thermal spark in air were evidenced:

1. Formation of a weakly ionized non-equilibrium plasma i.e. the non-equilibrium spark. The typical diameter at these early instants is $200-300 \mu \mathrm{m}$ and the emission is dominated by the $\mathrm{N}_{2}(\mathrm{C} \rightarrow \mathrm{B})$ radiative transition.

2. Generation of a filament at the cathode on a timescale below $0.5 \mathrm{~ns}$. The typical diameter of the filament is $100 \mu \mathrm{m}$; its emission is dominated by $\mathrm{N}^{+}$and a broadband continuum. The length and diameter of the filament is found to be independent of the pressure but varies with the applied electric field. 
3. A few nanoseconds later, formation of an anode filament with dimensions similar to those of the cathode filament.

4. Propagation of the two filaments in the interelectrode gap. The typical speed of propagation ranges between $10^{4}$ and $10^{5} \mathrm{~m} \mathrm{~s}^{-1}$ and is pressure dependent.

5. The filaments merge: the thermal spark is formed.

At low pressures (i.e. p $<300-400$ mbar), the thermal spark formation is interrupted at step 4 . However, step 5 could possibly occur with a longer discharge pulse.

We show that for the same deposited energy, at low and high pressures, the spark can be thermal or in non-equilibrium. The total deposited energy is therefore not an indicator of the transition to a thermal spark.

The electron number density evolution in the post-discharge of a thermal spark in air at 1 atm was measured by Stark broadening of $\mathrm{H}_{\alpha}$ and $\mathrm{N}^{+}$lines. Other broadening processes were found negligible or small, as shown in the appendix. The electron temperature, $T_{e}$, was measured by fitting the emission of excited electronic states of $\mathrm{N}^{+}$, with energies ranging from 21 to $30 \mathrm{eV}$. The electron number density was found to reach a maximum value of $4 \times 10^{19} \mathrm{~cm}^{-3}$ at the end of the pulse, and to then decay to $10^{17} \mathrm{~cm}^{-3}$ in $1000 \mathrm{~ns}$. We showed that the three-body recombination of electrons with $\mathrm{N}^{+}$is equilibrated by the reverse process of ionization of nitrogen excited states, even after the end of the voltage pulse. The decay of the electron number density is explained by isentropic expansion alone up to $t=100 \mathrm{~ns}$. Heat removal by conduction is found to be negligible on this timescale. Heat removal by radiation is more important but remains secondary. Therefore, for a complete simulation of the thermal spark afterglow, it is sufficient to consider a plasma in chemical equilibrium subject to volume expansion (and radiation losses). These conclusions are found to apply to other measurements performed in the recombination phase of thermal sparks $[9,12,13]$.

Finally, a comparison of $n_{e}$ and $T_{e}$ with values measured in a discharge typical of spark plugs used for internal combustion engine ignition showed that the nanosecond thermal spark is equivalent to the "breakdown phase" of the spark discharges used for flame ignition.

\section{Acknowledgments}

This work has been supported by the French National Research Agency (ANR-16-CE22-0005 PASTEC and ANR-16-CE30-0004 ASPEN) and the prematuration project DSP funded by IDEX 
Paris-Saclay. N. Minesi has been supported by an IDEX Ph.D. fellowship, ANR-11-IDEX-0003. The authors express their gratitude to E. Odic and M. Kirkpatrick for lending the spectrometer and the camera used for the present measurements. The authors would also like to thank P. Riviere, S. Macheret and M. Shneider for fruitful discussions, and Y. Le Teno, E. Jean-Bart and C. Oriot for technical assistance.

\section{Appendix: Calculation of line broadening contributions}

The lineshape of the observed atomic or ionic lines is due to natural, Van der Waals, Stark, resonant (Lorentzian profile) and Doppler (Gaussian profile) broadening mechanisms. The instrumental function of the spectrometer must also be considered. At the present conditions, self-absorption has no impact on the linewidth and is neglected. In this article, the Stark broadening widths of $\mathrm{O}^{+}$ (at $490 \mathrm{~nm}$ ), $\mathrm{N}^{+}$(at $500 \mathrm{~nm}$ ) and $\mathrm{H}_{\alpha}$ are used to determine the electron number density. In this appendix, the broadening widths of $\mathrm{H}_{\alpha}$ and of the $\mathrm{O}^{+}$and $\mathrm{N}^{+}$lines are calculated following the methods of Refs. [34,54]. We also performed these calculations for $\mathrm{H}_{\beta}, \mathrm{O}$ (at 777nm) and $\mathrm{N}$ (at $746 \mathrm{~nm}$ ) lines. The term "width" will refer to the Half Width at Half Maximum (HWHM).

Natural broadening, due to the uncertainty on the energy of the two states of the transition, can be calculated using Eq. 4 where $\lambda_{u l}$ is the transition wavelength, $c$ the speed of light, and $A_{u n}$ and $A_{l n}$ Einstein coefficients of the transition from level $u$ and $l$, respectively. This broadening is negligible and is not considered further here.

$$
\Delta \lambda_{\text {Natural }}=\frac{\lambda_{u l}^{2}}{4 \pi c}\left(\sum_{n<u} A_{u n}+\sum_{n<l} A_{l n}\right)
$$

Doppler broadening can be obtained from the following formula [54], where $T_{g a s}$ is the translational temperature and $M$ the molar mass of the emitter:

$$
\Delta \lambda_{\text {Doppler }}=3.58 \times 10^{-7} \lambda_{u l}[\mathrm{~nm}] \sqrt{\frac{T_{g a s}[K]}{M\left[g \cdot \mathrm{mol}^{-1}\right]}} \quad \text { Eq. } 5
$$

Van der Waals broadening is due to collisions between the emitter and other gas particles $[34,54,55]$. (A contribution from identical particles in states not radiatively linked to the radiating transition can be also considered [55]. This contribution is negligible in the present conditions and 
therefore will be neglected in our calculations.) The Van der Waals broadening width can be calculated using Eq. 6 [54]:

$$
\Delta \lambda_{\text {Van der Waals }}=0.98 \frac{\lambda_{u l}^{2}}{2 c}\left(\frac{9 \pi \hbar^{5} \overline{R^{2}}}{16 m_{e}^{3}}\right)^{\frac{2}{5}}\left(\frac{8 k T_{\text {gas }}}{\pi}\right)^{\frac{3}{10}} \sum_{\text {perturbers }}\left[\frac{N_{\text {perturbers }}}{E_{p}^{\frac{4}{5}} m_{r p}^{\frac{3}{10}}}\right] \quad \text { Eq. } 6
$$

where $m_{e}$ is the electron mass, $k$ the Boltzmann constant, $\hbar$ the Planck constant divided by $2 \pi$, and $N_{\text {perturbers }}$ the number density of the perturbers. The values of $E_{p}^{0.8} m_{r p}^{0.3}$ for the main perturbers $\left(\mathrm{O}, \mathrm{N}, \mathrm{O}^{+}, \mathrm{N}^{+}\right.$in the present work) are given in Table $3, m_{r p}$ being the reduced mass of the perturber-emitter system and $E_{p}$ the energy of the perturbing transition. The sum on the right-hand side of Eq. 6 requires knowledge of the gas composition. $\overline{R^{2}}$ is given in the following equation:

$$
\overline{R^{2}}=\overline{R_{u p}^{2}}-\overline{R_{\text {low }}^{2}}
$$

Eq. 7

$\overline{R_{\alpha}^{2}}$ is the mean square distance (in Bohr units) of the electron in orbital $l_{\alpha}$ and can be calculated using Eq. 8:

$$
\overline{R_{\alpha}^{2}} \approx \frac{1}{2} \frac{E_{H}}{E_{\infty}-E_{\alpha}}\left[5 \frac{z^{2} E_{H}}{E_{\infty}-E_{\alpha}}+1-3 l_{\alpha}\left(l_{\alpha}+1\right)\right]
$$

Eq. 8

where $E_{H}=13.6 \mathrm{eV}, E_{\infty}$ is the energy of ionization of the considered atom $(13.6 \mathrm{eV}$ for $\mathrm{H}$ and $\mathrm{O}$, $35.1 \mathrm{eV}$ for $\mathrm{O}^{+}, 14.5 \mathrm{eV}$ for $\mathrm{N}$ and $29.6 \mathrm{eV}$ for $\mathrm{N}^{+}$), $E_{\alpha}$ the energy of state $\alpha, l_{\alpha}$ the orbital quantum number of state $\alpha$ (see Table 4$)$, and $\mathrm{z}$ the number of effective charges $(\mathrm{z}=1$ for $\mathrm{H}$ or $\mathrm{N}$ and $\mathrm{z}=2$ for $\mathrm{N}^{+}$and $\mathrm{O}^{+}$). Taking the difference between the upper and lower state of the transition gives $\overline{R^{2}}$ in Eq. 7. Eq. 8 is exact only for hydrogen [56,57]. The term $\overline{R_{\text {low }}^{2}}$ is often neglected in the work of Griem [54,55]. If taken into account, it represents a difference of $11 \%$ and $3 \%$ for $\mathrm{H}_{\alpha}$ and $\mathrm{H}_{\beta}$ in the Van der Waals calculation. The difference reaches 39\% for the oxygen line at $777 \mathrm{~nm}$, which explains why our results differ slightly from Ref. [58]. In Table $4, \overline{R^{2}}$ is obtained by averaging the contribution of each $l_{\alpha}$ with their respective emission weight (Einstein coefficient times degeneracy, obtained from the NIST database [34]). Finally, we did not follow Griem's recommendation in his last book [55] to multiply the Van der Waals broadening by $N_{e}^{2 / 5}$, where $N_{e}$ is the number of valence electron of the perturbers, because this statement was not referenced, nor quoted or justified later. 
An equivalent formulation to Eq. 6, using the perturbing atom polarizability, can also be used [56,57,59]. For comparison, we consider the $\mathrm{N}$ transition at $742 \mathrm{~nm}$, in a gas composed of $\mathrm{N}_{2}$ at 1 bar and $300 \mathrm{~K}$. Applying the formulation of Refs. [56,57,59], with a polarizability of $1.77 \times 10^{-30}$ $\mathrm{m}^{3}$ [60], we obtain a Van der Waals HWHM of $0.021 \mathrm{~nm}$. If we apply the formulation of van der Horst [12], based on Ref. [59], we get a HWHM of $0.018 \mathrm{~nm}$. In the present work, with Eq. 6 and $\gamma_{N_{2} \rightarrow O}=1.26$ (Table 8), we get $0.013 \mathrm{~nm}$. This value is slightly lower, because the polarizability is implicitly simplified in Eq. 6, but remains however within the accuracy of the calculation.

Table 3 Contribution of various perturbers $\left(\mathrm{N}, \mathrm{O}, \mathrm{O}^{+}, \mathrm{N}^{+}, \mathrm{N}_{2}, \mathrm{O}_{2}, \mathrm{NO}\right.$ and $\left.\mathrm{H}_{2}\right)$ to the Van der Waals broadening of $\mathrm{H}, \mathrm{N}, \mathrm{N}^{+}, \mathrm{O}$, and $\mathrm{O}^{+}$. The contributions of $\mathrm{N}_{2}, \mathrm{O}_{2}$, and $\mathrm{NO}$ can be found in Ref. [34]. Data for $\mathrm{H}_{2}$ are taken from Ref. [61].

\begin{tabular}{|c|c|c|c|c|c|c|c|c|c|c|c|c|}
\hline \multicolumn{3}{|c|}{ Perturber } & \multicolumn{10}{|c|}{ Radiating atom } \\
\hline \multirow{2}{*}{ Species } & \multirow{2}{*}{$\begin{array}{l}\text { First allowed } \\
\text { transition to the } \\
\text { ground state }\end{array}$} & \multirow{2}{*}{$\begin{array}{c}E_{p} \\
(e V)\end{array}$} & \multicolumn{5}{|c|}{$m_{r p}-\mathrm{g} \cdot \mathrm{mol}^{-1}$} & \multicolumn{5}{|c|}{$E_{p}^{-\frac{4}{5}} m_{r p}^{-\frac{3}{10}}-\mathrm{eV}^{-0.8}\left(\mathrm{~g} \cdot \mathrm{mol}^{-1}\right)^{-0.3}$} \\
\hline & & & $\mathrm{H}$ & $\mathrm{N}^{+}$ & $\mathrm{N}$ & $\mathrm{O}^{+}$ & $\mathrm{O}$ & $\mathrm{H}$ & $\mathrm{N}^{+}$ & $\mathrm{N}$ & $\mathrm{O}^{+}$ & $\mathrm{O}$ \\
\hline $\mathrm{N}^{+}$ & ${ }^{3} \mathrm{D} \rightarrow{ }^{3} \mathrm{P}$ & 11.4 & 0.93 & - & 7 & 7.4 & 7.4 & 0.15 & - & 0.079 & 0.078 & 0.078 \\
\hline $\mathrm{N}$ & ${ }^{4} \mathrm{P} \rightarrow{ }^{4} \mathrm{~S}^{0}$ & 10.3 & 0.93 & 7 & - & 7.4 & 7.4 & 0.16 & 0.086 & - & 0.084 & 0.084 \\
\hline $\mathrm{O}^{+}$ & ${ }^{4} \mathrm{P} \rightarrow{ }^{4} \mathrm{~S}$ & 14.9 & 0.94 & 7.47 & 7.47 & - & 8 & 0.12 & 0.063 & 0.063 & - & 0.061 \\
\hline $\mathrm{O}$ & ${ }^{3} \mathrm{~S}^{0} \rightarrow{ }^{3} \mathrm{P}$ & 9.5 & 0.94 & 7.47 & 7.47 & 8 & - & 0.17 & 0.09 & 0.09 & 0.088 & - \\
\hline $\mathrm{O}_{2}$ & $\mathrm{~B}^{3} \Sigma_{u}^{-} \rightarrow \mathrm{X}^{3} \Sigma_{g}^{-}$ & 6.2 & 0.97 & 9.74 & 9.74 & 10.67 & 10.67 & 0.23 & 0.12 & 0.12 & 0.11 & 0.11 \\
\hline $\mathrm{N}_{2}$ & $\mathrm{~b}^{1} \Pi_{\mathrm{u}} \rightarrow \mathrm{X}^{1} \Sigma_{g}^{+}$ & 12.6 & 0.97 & 9.33 & 9.33 & 10.18 & 10.18 & 0.13 & 0.07 & 0.07 & 0.07 & 0.07 \\
\hline $\mathrm{NO}$ & $\mathrm{A}^{2} \Sigma^{+} \rightarrow \mathrm{X}^{2} \Pi$ & 5.5 & 0.97 & 9.55 & 9.55 & 10.43 & 10.43 & 0.26 & 0.13 & 0.13 & 0.13 & 0.13 \\
\hline $\mathrm{H}_{2}$ & $\mathrm{~B}^{1} \Sigma_{u}^{+} \rightarrow \mathrm{X}^{1} \Sigma_{g}^{+}$ & 11.2 & 0.67 & 1.75 & 1.75 & 1.78 & 1.78 & 0.16 & 0.12 & 0.12 & 0.12 & 0.12 \\
\hline
\end{tabular}

Table 4 Constants used for the calculation of $\overline{R^{2}}$. The $N^{+}$and $O^{+}$lines (at $500 \mathrm{~nm}$ and $470 \mathrm{~nm}$, respectively) are comprised of 15 and 12 transitions, respectively [31], and only major lines are shown.

\begin{tabular}{|c|c|c|c|c|c|c|c|}
\hline \multirow{2}{*}{ Transition } & \multicolumn{2}{|c|}{ Upper State } & \multicolumn{2}{|c|}{ Lower State } & \multirow{2}{*}{$\overline{R^{2}}$} & \multirow{2}{*}{ Weight (\%) } & \multirow{2}{*}{$\left\langle\overline{R^{2}}\right\rangle^{2 / 5}$} \\
\hline & $E_{\text {low }}(\mathrm{eV})$ & Conf. - $1_{\text {low }}$ & $E_{u p}(\mathrm{eV})$ & Conf. - $1_{\text {up }}$ & & & \\
\hline & 12.09 & $3 s-0$ & 10.20 & $2 p-1$ & 177 & $2 \%$ & 6.4 \\
\hline
\end{tabular}




\begin{tabular}{|c|c|c|c|c|c|c|c|}
\hline $\mathrm{H}_{\alpha}$ & & $\begin{array}{l}3 p-1 \\
3 d-2\end{array}$ & & $\begin{array}{l}2 s-0 \\
2 p-1\end{array}$ & $\begin{array}{l}138 \\
96\end{array}$ & $\begin{array}{l}17 \% \\
81 \%\end{array}$ & \\
\hline $\mathrm{H}_{\beta}$ & 12.75 & $\begin{array}{l}4 s-0 \\
4 p-1 \\
4 d-2\end{array}$ & 10.20 & $\begin{array}{l}2 p-1 \\
2 s-0 \\
2 p-1\end{array}$ & $\begin{array}{l}618 \\
558 \\
474\end{array}$ & $\begin{array}{l}2 \% \\
21 \% \\
77 \%\end{array}$ & 12.0 \\
\hline $\begin{array}{l}\mathrm{N}-742.37 \mathrm{~nm} \\
\mathrm{~N}-744.23 \mathrm{~nm} \\
\mathrm{~N}-746.83 \mathrm{~nm}\end{array}$ & 11.996 & $3 p-1$ & $\begin{array}{l}12.325 \\
12.330 \\
12.335\end{array}$ & $3 s-0$ & 31 & $\begin{array}{l}12 \% \\
25 \% \\
63 \%\end{array}$ & 3.9 \\
\hline $\begin{array}{l}\mathrm{N}^{+}-500.52 \mathrm{~nm} \\
\mathrm{~N}^{+}-500.15 \mathrm{~nm} \\
\mathrm{~N}^{+}-500.11 \mathrm{~nm}\end{array}$ & $\begin{array}{l}23.14 \\
23.13 \\
23.13\end{array}$ & $3 d-2$ & $\begin{array}{l}20.67 \\
20.65 \\
20.65\end{array}$ & $3 p-1$ & $\begin{array}{l}7.1 \\
7.0 \\
7.0\end{array}$ & $\begin{array}{l}25 \% \\
18 \% \\
12 \%\end{array}$ & \multirow[t]{2}{*}{7.3} \\
\hline$\ldots$ & $\ldots$ & $\ldots$ & $\ldots$ & $\ldots$ & $\ldots$ & $\ldots$ & \\
\hline $\begin{array}{l}\mathrm{O}-777.19 \mathrm{~nm} \\
\mathrm{O}-777.42 \mathrm{~nm} \\
\mathrm{O}-777.54 \mathrm{~nm}\end{array}$ & 10.74 & $3 p-1$ & 9.15 & $3 s-0$ & 19 & $\begin{array}{l}4 \% \\
33 \% \\
20 \%\end{array}$ & 3.3 \\
\hline $\begin{array}{l}\mathrm{O}^{+}-470.54 \mathrm{~nm} \\
\mathrm{O}^{+}-469.90 \mathrm{~nm}\end{array}$ & $\begin{array}{l}28.88 \\
31.15\end{array}$ & \multirow{3}{*}{$3 d-2$} & $\begin{array}{l}26.25 \\
28.51\end{array}$ & \multirow{3}{*}{$3 p-1$} & $\begin{array}{c}9.33 \\
51\end{array}$ & $\begin{array}{l}17 \% \\
15 \%\end{array}$ & \multirow{4}{*}{4.4} \\
\hline $\mathrm{O}^{+}-469.92 \mathrm{~nm}$ & 28.86 & & 26.23 & & 9.2 & $14 \%$ & \\
\hline $\begin{array}{l}\mathrm{O}^{+}-470.12 \mathrm{~nm} \\
\mathrm{O}^{+}-470.32 \mathrm{~nm}\end{array}$ & $\begin{array}{l}31.47 \\
31.15\end{array}$ & & $\begin{array}{l}28.83 \\
28.51\end{array}$ & & $\begin{array}{l}65 \\
51\end{array}$ & $\begin{array}{l}14 \% \\
14 \%\end{array}$ & \\
\hline$\ldots$ & $\ldots$ & $\ldots$ & $\ldots$ & $\ldots$ & $\ldots$ & $\ldots$ & \\
\hline
\end{tabular}

Resonant broadening is due to the interaction of the radiating atom with other like-atoms in states radiatively linked to the upper (u) or lower (1) level of the transition. In Ref. [34], the theory of resonant broadening was based on the book of Griem published in 1964 [54], and took into account the contributions of three states of the perturbing atom radiatively linked to the radiating atom: (i) $\mathrm{g} \rightarrow \mathrm{u}$, (ii) $\mathrm{g} \rightarrow 1$, and (iii) $1 \rightarrow \mathrm{u}$, where $g$ is the ground state.

Later, Ali and Griem [62,63] published improvements and corrections that were taken into account in other publications, such as Refs. [55,59,64,65]. The correction of Ali and Griem leads to resonant broadening width 1.6 times higher than with the non-corrected formula of Laux et al. [34]. The corrected formulation is shown in Eq. 9 


$$
\Delta \lambda_{\text {Res }}=\frac{8,61 \times 10^{-28}}{2} \lambda_{u l}^{2}\left[\lambda_{u g} f_{g u} \sqrt{\frac{g_{g}}{g_{u}}} n_{g}+\lambda_{l g} f_{g l} \sqrt{\frac{g_{g}}{g_{l}}} n_{g}+\lambda_{u l} f_{l u} \sqrt{\frac{g_{l}}{g_{u}}} n_{l}+\cdots\right] \quad \text { Eq. } 9
$$

where $\lambda_{a b}$ is the wavelength (in $\mathrm{nm}$ ) of the transition between $a$ and $b, f_{a b}$ the (absorption)

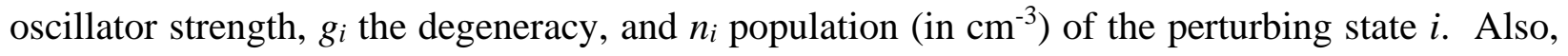
we note that Ref. [34] considered the perturbation (i) of $1 \rightarrow \mathrm{u}$, but the population of state 1 is usually so low (less than $1 \%$ of the states at $10,000 \mathrm{~K}$ in the case of $\mathrm{H}_{\alpha}$ ) that its contribution is often neglected by other authors. In this work, we considered other resonant states of the perturber with energies below a certain threshold indicated in Table 5. For $\mathrm{H}_{\alpha}$ and $\mathrm{H}_{\beta}$, all the resonant levels below the upper level of the transition were included in the calculation. This means for $\mathrm{H}_{\beta}$ that we calculated the resonance of $n=1 \rightarrow n=4, n=1 \rightarrow n=2, n=2 \rightarrow n=4$ and $n=3 \rightarrow n=4$. The effect of these supplementary resonant states has an impact on the calculation for $\mathrm{H}_{\beta}$ and $\mathrm{O}^{+}$with a maximal increase of $50 \%$ and $97 \%$ in the $1000-50,000 \mathrm{~K}$ range, compared to the calculation with only the ground state. For other atoms and ions, the effect was negligible or null.

Table 5 Coefficient $\beta$ tabulated from 1000 to 50,000 K. All the states under the specified threshold energy were considered in the calculation.

\begin{tabular}{|c|c|c|c|c|c|c|}
\hline$T_{e}(\mathrm{~K})$ & $\begin{array}{c}\mathrm{H}_{\alpha} \\
656 \mathrm{~nm}\end{array}$ & $\begin{array}{c}\mathrm{H}_{\beta} \\
495 \mathrm{~nm}\end{array}$ & $\begin{array}{c}\mathrm{N} \\
746.831 \mathrm{~nm}\end{array}$ & $\begin{array}{c}\mathrm{N}^{+} \\
500 \mathrm{~nm}\end{array}$ & $\begin{array}{c}\mathrm{O} \\
777 \mathrm{~nm}\end{array}$ & $\begin{array}{c}\mathrm{O}^{+} \\
470 \mathrm{~nm}\end{array}$ \\
\hline 1000 & 0.52 & $7.1 \times 10^{-2}$ & $8.3 \times 10^{-2}$ & $5.1 \times 10^{-4}$ & $3.9 \times 10^{-7}$ & $6.0 \times 10^{-6}$ \\
\hline 10,000 & 0.51 & $7.0 \times 10^{-2}$ & $7.0 \times 10^{-2}$ & $4.9 \times 10^{-5}$ & $8.6 \times 10^{-6}$ & $2.1 \times 10^{-5}$ \\
\hline 20,000 & $5.5 \times 10^{-2}$ & $1.0 \times 10^{-2}$ & $4.2 \times 10^{-2}$ & $4.6 \times 10^{-5}$ & $1.4 \times 10^{-3}$ & $8.4 \times 10^{-5}$ \\
\hline 30,000 & $4.1 \times 10^{-3}$ & $2.3 \times 10^{-3}$ & $2.2 \times 10^{-2}$ & $4.8 \times 10^{-5}$ & $4.3 \times 10^{-3}$ & $1.2 \times 10^{-4}$ \\
\hline 40,000 & $1.7 \times 10^{-3}$ & $2.0 \times 10^{-3}$ & $1.2 \times 10^{-2}$ & $6.3 \times 10^{-5}$ & $4.5 \times 10^{-3}$ & $1.4 \times 10^{-4}$ \\
\hline 50,000 & $1.0 \times 10^{-3}$ & $1.9 \times 10^{-3}$ & $7.2 \times 10^{-3}$ & $9.1 \times 10^{-5}$ & $3.7 \times 10^{-3}$ & $1.5 \times 10^{-4}$ \\
\hline $\begin{array}{c}\text { Threshold } \\
(\mathrm{eV})\end{array}$ & 12.1 & 12.8 & 3.6 & 13.6 & 4.2 & 5.1 \\
\hline
\end{tabular}

A "unified theory" of resonant broadening for the $\mathrm{H}_{\alpha}$ line (including higher-order interaction potentials) was developed in Ref. [66]. We use this theory for comparison with the present estimates. From [66, Table 2], a density of atomic hydrogen $n_{H}=10^{17} \mathrm{~cm}^{-3}$ at a temperature $T=12,000 \mathrm{~K}$ leads to a resonant HWHM of $\mathrm{H}_{\alpha}$ of $8.4 \times 10^{-4} \mathrm{~nm}$; when using [59,62,63] (Griem corrected) we obtain $16.0 \times 10^{-4} \mathrm{~nm}$ and using [34,54] (Griem non-corrected) we have $10.0 \times 10^{-4}$ 
$\mathrm{nm}$. The difference being small, the corrected formula taken from $[59,62,63]$ is used in the present work.

In summary, the resonant broadening widths of $\mathrm{N}^{+}$at $500 \mathrm{~nm}, \mathrm{~N}$ at $746.831 \mathrm{~nm}, \mathrm{O}$ at $777 \mathrm{~nm}, \mathrm{H}_{\alpha}$ and $\mathrm{H}_{\beta}$ can be calculated with Eq. 15, using the $\beta$ coefficients in Table 5 and Table 7 . For O, the resonant broadening of the three lines is averaged with their respective emission weight in a similar way than what is shown in Table 4. The same procedure is applied for $\mathrm{N}^{+}$and $\mathrm{O}^{+}$. For $\mathrm{N}$ emission at 744.229 and $742.364 \mathrm{~nm}$, the results of $\mathrm{N}$ emission at $746.831 \mathrm{~nm}$ can be taken within a maximal difference of a factor 2 .

Stark broadening is directly related to the electron number density: the relation is in a first approximation linear for all emitting species, except hydrogen. Therefore, using the database of Konjevic et al. [38] or the calculated coefficient of Griem in Ref. [35, p. 370] (updated and different from his previous book [54]), one can convert a Stark width to an electron number density. Stark broadening of hydrogen is accurately calculated by Gigosos et al. [37,67]. In their papers, Gigosos et al. recommend using the Full Width at Half Area (FWHA) instead of the classical FWHM to characterize Stark broadening, since the FWHA is less dependent on the ion temperature. However, in the case of $\mathrm{H}_{\alpha}$, the Stark broadening of the line is close to a Lorentzian shape and it can be assumed FWHA = FWHM [68]. Therefore, the $\mathrm{H}_{\alpha}$ line is fitted by a Lorentzian profile convolved with the instrumental broadening function, and the electron number density is obtained using Eq. 10 after subtraction of the other Lorentzian broadenings.

$$
\Delta \lambda_{H W H M, \mathrm{H} \alpha}[\mathrm{nm}]=0.549 \times\left(\frac{n_{e}}{10^{23} m^{-3}}\right)^{0.67965} \quad \text { Eq. } 10
$$

It was pointed out in Ref. [68] that what was called FWHM by Gigosos et al. in Ref. [37] is, in fact, the HWHM. A typical fit of the $\mathrm{H}_{\alpha}$ line is shown in Figure 12. The Stark shift of $\mathrm{H}_{\alpha}$ can be related to its Stark broadening width, according to Eq. 11.

$$
H_{\alpha}: \Delta \lambda_{\text {Stark }}[\mathrm{nm}]=\frac{1}{2}\left(\frac{s_{\text {Stark }}[\mathrm{nm}]}{0.056}\right)^{2 / 3}
$$

The relation is non-linear and can be discriminated from the Van der Waals shift, Eq. 12.

$$
\Delta \lambda_{\text {Van der Waals }}[\mathrm{nm}]=\frac{3}{2} S_{\text {Van der Waals }}[\mathrm{nm}] \quad \text { Eq. } 12
$$

In Figure 16, the measured shifts and measured Lorentzian widths of $\mathrm{H}_{\alpha}$ are reported and compared to the theoretical relations of Eq. 11 and Eq. 12. The measurements clearly show that the main 
broadening effect is due to the Stark effect. This approach was already used by Sainct et al. [11] to confirm that, in their work, the measured $\mathrm{H}_{\alpha}$ broadening widths were due to the Stark effect.

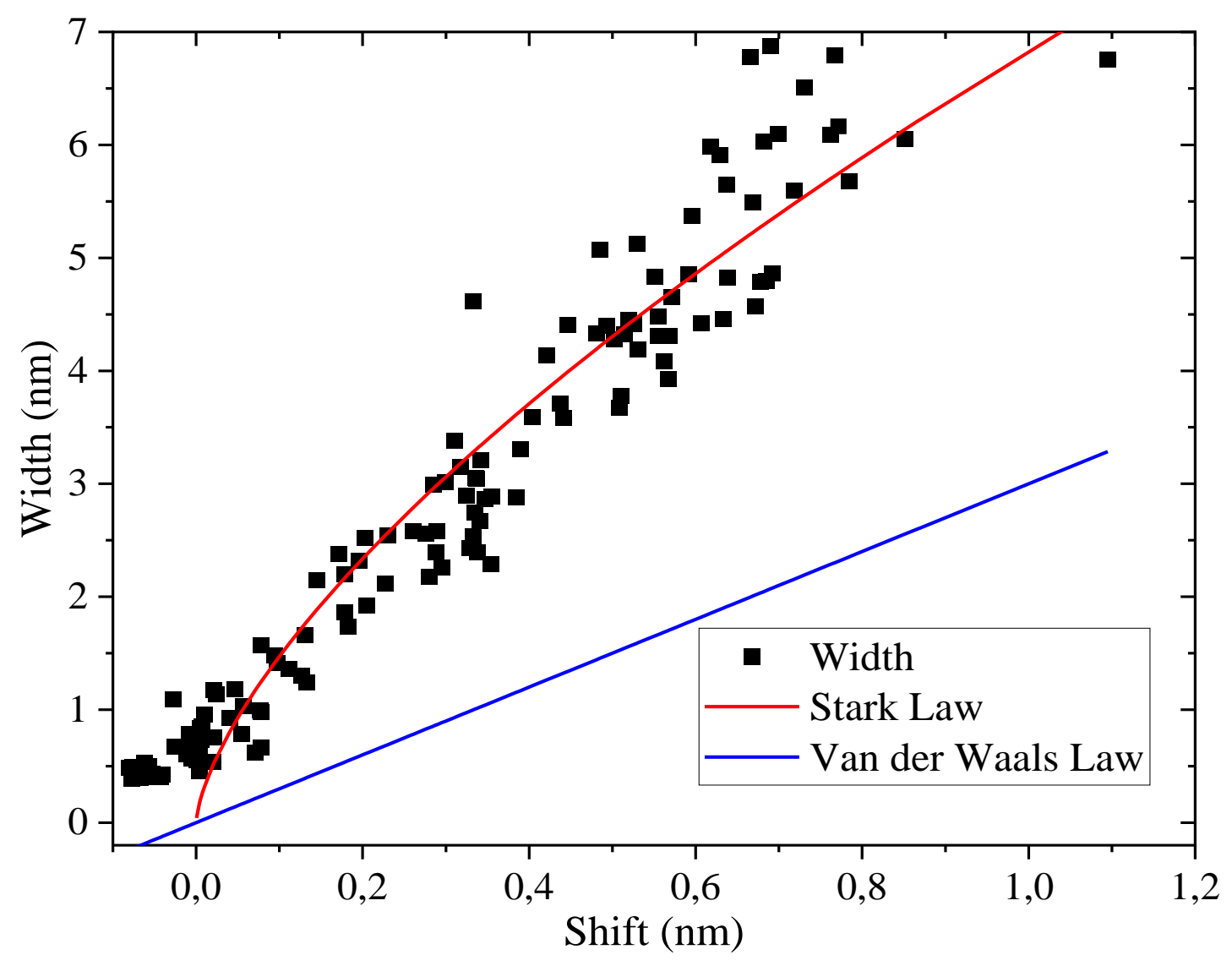

Figure 16 Fitted widths as a function of the corresponding shifts. The measurements correspond to the data shown in Figure 13.

The Stark coefficients of $\mathrm{N}^{+}$and $\mathrm{O}^{+}$are implemented in an in-house development of SPECAIR [33,34] using the coefficients calculated by Griem [35]. The tables of Griem give the reference coefficients, $\omega_{\text {Stark,ref }}$, at $n_{e}=10^{17} \mathrm{~cm}^{-3}$ and the Stark broadening at a given $n_{e}$ is obtained using Eq. 13. Since Stark broadening of $\mathrm{O}, \mathrm{O}^{+}, \mathrm{N}$ and $\mathrm{N}^{+}$by ions is negligible, the effect of ions is not considered in our in-house extension of SPECAIR.

$$
\omega_{\text {Stark }}=\frac{n_{e}}{10^{17} \mathrm{~cm}^{-3}} \omega_{\text {Stark,ref }}
$$

Stark broadening coefficients for the $\mathrm{N}^{+}$transitions at $519 \mathrm{~nm}$ are not given in the book of Griem. Based on our measurements, we find that the lines at $519 \mathrm{~nm}$ are well fitted using Eq. 13 by a coefficient $\omega_{\text {Stark }, 519 \mathrm{~nm}}=0.015 \mathrm{~nm}$. This coefficient is consistent with the values measured by Mar et al. [69] and calculated by Riviere [70] as shown in Table 6. The agreement is illustrated in 
Figure 17 where the data of Table 6 are reported with the corresponding error bars $[38,69,70]$. The uncertainty on the $\mathrm{x}$-axis corresponds to the range of temperatures measured in this work $(30,000$ $-50,000 \mathrm{~K}$ range). The uncertainty on the value itself is the sum of (i) the uncertainty of the $n_{e}$ measurement $( \pm 10 \%)$ and (ii) the variation of the coefficient on the temperature range supposed, in a first approximation, to vary with $T_{e}^{-0.5}( \pm 20 \%)$. The three lines $(519.038,518.20$ and 518.621 $\mathrm{nm}$ ) composing the emission at $519 \mathrm{~nm}$ could not be resolved because of their broad Stark widths. Thus, the coefficients of the ${ }^{5} \mathrm{D}$ and ${ }^{5} \mathrm{P}$ transitions are assumed to be equal.

Table 6 Empirical Stark coefficients of $N^{+}$used in this article for determination of the Stark HWHM. For comparison, other values are extracted from the review of Konjevic et al. [38] at $n_{e}=10^{17} \mathrm{~cm}^{-3}$ and $T_{e}=$ $28 \mathrm{kK}$ (original experimental work of Mar et al. [69]). Calculated values based on the method of Griem [54] are from Riviere [70].

\begin{tabular}{|c|c|c|c|c|c|}
\hline \multirow{2}{*}{$\begin{array}{l}\text { Lower Conf. } \\
\text { Lower Term }\end{array}$} & \multirow{2}{*}{$\begin{array}{l}\text { Upper Conf. } \\
\text { Upper Term }\end{array}$} & \multirow{2}{*}{$\lambda(\mathrm{nm})$} & \multicolumn{3}{|c|}{$\begin{array}{c}\omega_{\text {Stark }}(\mathrm{HWHM}-\mathrm{nm}) \\
n_{e}=10^{17} \mathrm{~cm}^{-3}\end{array}$} \\
\hline & & & $\begin{array}{c}\text { Riviere }[70] \\
\mathrm{T}_{\mathrm{e}}=25 \mathrm{kK}\end{array}$ & $\begin{array}{c}\text { Mar et al. [69] } \\
\mathrm{T}_{\mathrm{e}}=28 \mathrm{kK}\end{array}$ & $\begin{array}{c}\text { This work } \\
\mathrm{Te}=30-50 \mathrm{kK}\end{array}$ \\
\hline$\frac{2 \mathrm{~s} .2 \mathrm{p} 2.3 \mathrm{~d}}{{ }^{5} \mathrm{~F}}$ & $\begin{array}{l}2 \mathrm{~s} .2 \mathrm{p} 2.3 \mathrm{p} \\
{ }^{5} \mathrm{D}^{0}\end{array}$ & 519.038 & 0.0273 & 0.0219 & 0.015 \\
\hline $\begin{array}{l}2 \mathrm{~s} .2 \mathrm{p} 2.3 \mathrm{~d} \\
{ }^{5} \mathrm{D}\end{array}$ & $\begin{array}{l}2 \mathrm{~s} .2 \mathrm{p} 2.3 \mathrm{p} \\
{ }_{5} \mathrm{P}^{0}\end{array}$ & $\begin{array}{c}518.20 \\
518.621\end{array}$ & $\begin{array}{l}0.0296 \\
0.0297\end{array}$ & $\begin{array}{c}0.0241 \\
0.02445\end{array}$ & 0.015 \\
\hline
\end{tabular}

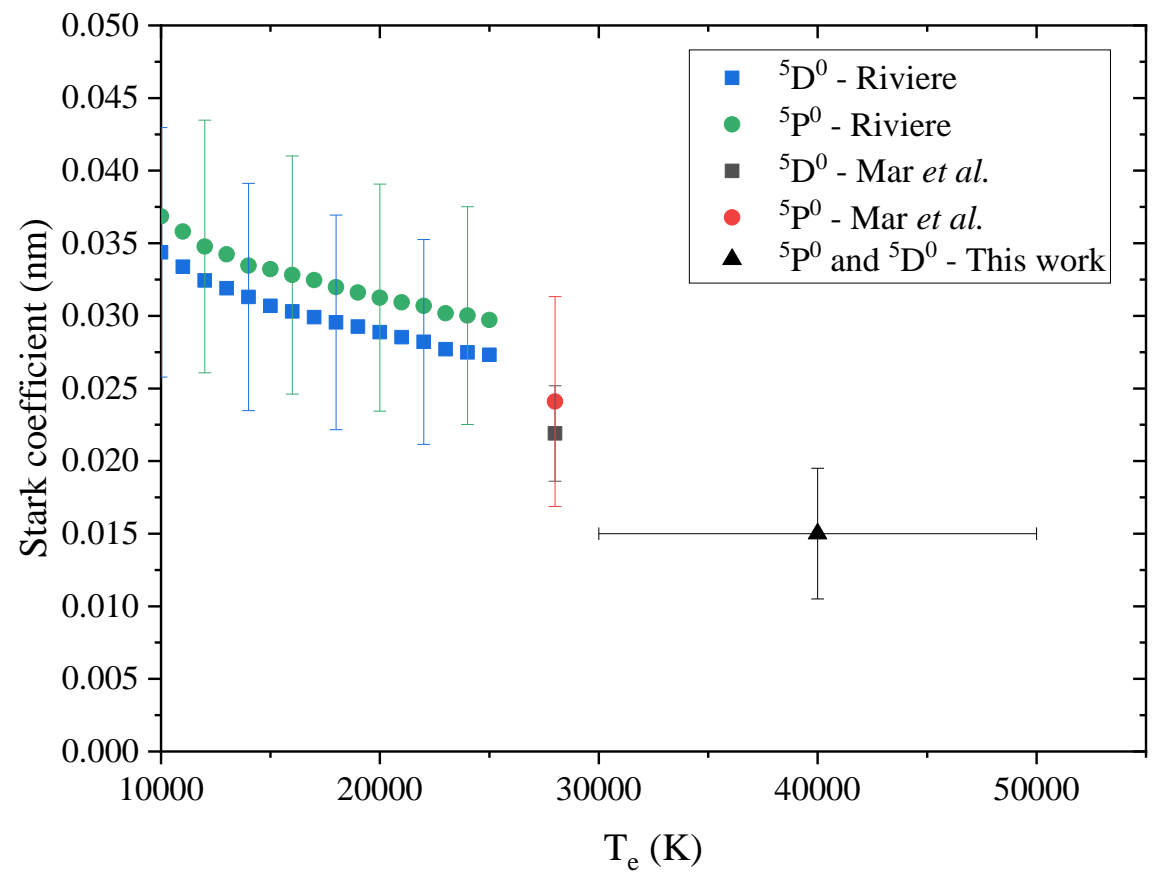

Figure 17 Comparison of the Stark coefficient values for the $N^{+}$lines at $519 \mathrm{~nm}$ from Riviere [70], Mar et al.[69] and this work 
The broadening HWHM formulas for $\mathrm{H}_{\alpha}, \mathrm{H}_{\beta}, \mathrm{O}, \mathrm{O}^{+}, \mathrm{N}$, and $\mathrm{N}^{+}$are summarized in Eq. 14 - Eq. 16. The coefficients $\alpha, \beta$, and $\gamma$ are given in Table 7 . The reference density of $2.7 \times 10^{19} \mathrm{~cm}^{-3}$ is the total gas density at $273 \mathrm{~K}, 1 \mathrm{~atm}$ (Loschmidt constant).

$$
\begin{gathered}
\Delta \lambda_{\text {Doppler }}[\mathrm{nm}]=\alpha \sqrt{\frac{T}{273 \mathrm{~K}}} \\
\Delta \lambda_{\text {resonance }}[\mathrm{nm}]=\beta \frac{n_{\text {emitter }}}{2.7 \times 10^{19} \mathrm{~cm}^{-3}} \\
\Delta \lambda_{\text {Van der Waals }}[\mathrm{nm}]=\sum_{\text {pert }} \frac{\gamma_{\text {pert }}}{100} \times \frac{n_{\text {pert }}}{2.7 \times 10^{19} \mathrm{~cm}^{-3}}\left(\frac{T_{\text {gas }}}{273 \mathrm{~K}}\right)^{0.3}
\end{gathered}
$$

We can also rewrite Eq. 16 using the molar fraction, $x_{p e r t}$, and the pressure, $p$, as sometimes done in the literature [12,34]:

$$
\begin{aligned}
\Delta \lambda_{\text {Van der Waals }}[\mathrm{nm}] & =\frac{n_{\text {total }}}{2.7 \times 10^{19} \mathrm{~cm}^{-3}}\left(\frac{T_{\text {gas }}}{273 \mathrm{~K}}\right)^{0.3} \sum_{\text {pert }}\left(\frac{\gamma_{\text {pert }}}{100} x_{\text {pert }}\right) \\
& =\frac{p}{1 \mathrm{~atm}}\left(\frac{273 \mathrm{~K}}{T_{\text {gas }}}\right)^{0.7} \sum_{\text {pert }}\left(\frac{\gamma_{\text {pert }}}{100} x_{\text {pert }}\right)
\end{aligned}
$$

Complementary Van der Waals coefficients, $\gamma$, are given in Table 8 for the following collision partners: $\mathrm{N}_{2}, \mathrm{O}_{2}, \mathrm{NO}, \mathrm{CO}, \mathrm{CO}_{2}, \mathrm{CH}_{4}, \mathrm{H}_{2} \mathrm{O}, \mathrm{H}_{2}$, and Ar. The $\gamma$ coefficient being proportional to the collider polarizability, $\alpha_{C}$, we multiplied $\gamma_{N_{2}}$ by $\left(\alpha_{C} / \alpha_{N_{2}}\right)^{2 / 5}$ to get the $\gamma_{C}$ coefficients of $C=\mathrm{CO}$, $\mathrm{CO}_{2}, \mathrm{CH}_{4}, \mathrm{H}_{2} \mathrm{O}$, and $\mathrm{Ar}\left[60\right.$, p. 668]. For instance, we obtain $\gamma_{\mathrm{CO}_{2} \rightarrow H_{\alpha}}=3.43$ using the polarizability ratio of $\mathrm{N}_{2}$ and $\mathrm{CO}_{2}$. The same result can be obtained, knowing that the first excited state of $\mathrm{CO}_{2}$ radiatively linked to the ground state is ${ }^{1} \Pi_{\mathrm{g}}$ at $8.9 \mathrm{eV}$ [30, Table 4.1], giving a factor $E_{p}^{-0.8} m_{r p}^{-0.3}=0.20 \mathrm{eV}^{-0.8}\left(\mathrm{~g} \cdot \mathrm{mol}^{-1}\right)^{-0.3}$, which results in $\gamma_{\mathrm{CO}_{2} \rightarrow H_{\alpha}}=4.51$. 
Table 7 Summary of the simplified formulas for HWHM determination and tabulated coefficients $\alpha, \beta$ and $\gamma$. The broadening expressions derived in this work are shown in the first line. The $\alpha$ coefficient is exact. The $\beta$ coefficient is calculated at $T_{e}=30,000 \mathrm{~K}$.

\begin{tabular}{|c|c|c|c|c|c|c|}
\hline \multirow[t]{3}{*}{ Transition } & \multirow[t]{3}{*}{$\begin{array}{c}\text { Gaussian Broadening } \\
\Delta \lambda_{\text {Doppler }}[\mathrm{nm}] \\
\alpha \sqrt{\frac{T}{300 K}}\end{array}$} & $\Delta \lambda_{\text {Van de }}$ & $\begin{array}{r}\text { Loren } \\
\Delta \lambda_{\text {resonance }}[n \\
\text { Waals }[n m]=\sum_{\text {per }}\end{array}$ & $\begin{array}{l}\text { zian Broadening } \\
n]=\beta \frac{n_{\text {emi }}}{2.7 \times 10} \\
\frac{\gamma_{\text {pert }}}{100} \times \frac{n_{p}}{2.7 \times 10}\end{array}$ & $\begin{array}{l}\frac{\text { ter }}{{ }^{9} \mathrm{~cm}^{-3}} \\
\frac{{ }^{e r t} \mathrm{~cm}^{-3}}{{ }^{-3}}\left(\frac{T_{\text {gas }}}{273 \mathrm{~K}}\right.\end{array}$ & 0.3 \\
\hline & & \multirow[b]{2}{*}{$\begin{array}{c}\beta[n m] \\
\left(T_{e}=30,000 \mathrm{~K}\right)\end{array}$} & \multicolumn{4}{|c|}{$\gamma[\mathrm{nm}]$} \\
\hline & & & $\mathrm{N}^{+}$ & $\mathrm{N}$ & $\mathrm{O}$ & $\mathrm{O}^{+}$ \\
\hline $\mathrm{H}_{\alpha}(656 \mathrm{~nm})$ & $\alpha_{H_{\alpha}}=3.87 \times 10^{-3}$ & $\beta_{H_{\alpha}}=4.1 \times 10^{-3}$ & $\gamma_{N^{+} \rightarrow H_{\alpha}}=3.4$ & $\gamma_{N \rightarrow H_{\alpha}}=3.6$ & $\gamma_{O \rightarrow H_{\alpha}}=3.8$ & $\gamma_{O^{+} \rightarrow H_{\alpha}}=2.7$ \\
\hline $\mathrm{H}_{\beta}(486 \mathrm{~nm})$ & $\alpha_{H_{\beta}}=2.87 \times 10^{-3}$ & $\beta_{H_{\beta}}=2.3 \times 10^{-3}$ & $\gamma_{N^{+} \rightarrow H_{\beta}}=3.5$ & $\gamma_{N \rightarrow H_{\beta}}=3.7$ & $\gamma_{O \rightarrow H_{\beta}}=3.9$ & $\gamma_{O^{+} \rightarrow H_{\beta}}=2.7$ \\
\hline $\mathrm{N}^{+}(500 \mathrm{~nm})$ & $\alpha_{N^{+}}=0.78 \times 10^{-3}$ & $\beta_{N^{+}, 500}=4.8 \times 10^{-5}$ & -- & $\gamma_{N \rightarrow N^{+}}=1.3$ & $\gamma_{O \rightarrow N^{+}}=1.4$ & $\gamma_{O^{+} \rightarrow N^{+}}=0.95$ \\
\hline $\mathrm{N}(746 \mathrm{~nm})$ & $\alpha_{N}=1.18 \times 10^{-3}$ & $\beta_{N, 746}=2.2 \times 10^{-2}$ & $\gamma_{N^{+} \rightarrow N}=1.4$ & -- & $\gamma_{O \rightarrow N}=1.6$ & $\gamma_{O^{+} \rightarrow N}=1.1$ \\
\hline $\mathrm{O}(777 \mathrm{~nm})$ & $\alpha_{O}=1.15 \times 10^{-3}$ & $\beta_{O, 777}=4.3 \times 10^{-3}$ & $\gamma_{N^{+} \rightarrow O}=1.3$ & $\gamma_{N \rightarrow O}=1.4$ & -- & $\gamma_{O^{+} \rightarrow O}=0.99$ \\
\hline $\mathrm{O}^{+}(470 \mathrm{~nm})$ & $\alpha_{O^{+}}=0.69 \times 10^{-3}$ & $\beta_{O^{+}, 470}=1.2 \times 10^{-4}$ & $\gamma_{N^{+} \rightarrow O^{+}}=0.62$ & $\gamma_{N \rightarrow O^{+}}=0.67$ & $\gamma_{O \rightarrow O^{+}}=0.70$ & -- \\
\hline
\end{tabular}


1 Table 8 Coefficient $\gamma$ tabulated for Van der Waals broadening by the following colliders: $\mathrm{N}_{2}, \mathrm{O}_{2}, \mathrm{NO}, \mathrm{CO}_{2}$,

$2 \mathrm{CO}, \mathrm{CH}_{4}, \mathrm{H}_{2} \mathrm{O}, \mathrm{H}_{2}$, and $\mathrm{Ar}$.

\begin{tabular}{|c||c|c|c|c|c|c|c|c|c|}
\hline Perturbing & $\mathrm{N}_{2}$ & $\mathrm{O}_{2}$ & $\mathrm{NO}$ & $\mathrm{H}_{2}$ & $\mathrm{CO}_{2}$ & $\mathrm{CO}$ & $\mathrm{H}_{2} \mathrm{O}$ & $\mathrm{CH}_{4}$ & $\mathrm{Ar}$ \\
\hline \begin{tabular}{c}
\hline $\mathrm{H}_{\alpha}$ \\
$(656 \mathrm{~nm})$
\end{tabular} & 2.9 & 5.2 & 5.9 & 3.6 & 3.4 & 3.1 & 2.7 & 3.4 & 2.8 \\
\hline $\begin{array}{c}\mathrm{H}_{\beta} \\
(486 \mathrm{~nm})\end{array}$ & 3.0 & 5.3 & 6.0 & 3.7 & 3.5 & 3.2 & 2.8 & 3.5 & 2.9 \\
\hline $\begin{array}{c}\mathrm{N}^{+} \\
(500 \mathrm{~nm})\end{array}$ & 1.0 & 1.8 & 2.0 & 1.8 & 1.2 & 1.1 & 1.0 & 1.2 & 1.0 \\
\hline $\begin{array}{c}\mathrm{N} \\
(746 \mathrm{~nm})\end{array}$ & 1.3 & 2.2 & 2.3 & 2.2 & 1.5 & 1.3 & 1.2 & 1.5 & 1.2 \\
\hline $\begin{array}{c}\mathrm{O} \\
(777 \mathrm{~nm})\end{array}$ & 1.1 & 1.8 & 2.1 & 1.9 & 1.3 & 1.2 & 1.1 & 1.3 & 1.1 \\
\hline $\begin{array}{c}\mathrm{O}^{+} \\
(470 \mathrm{~nm})\end{array}$ & 0.6 & 0.9 & 1.0 & 1.0 & 0.7 & 0.6 & 0.5 & 0.7 & 0.5 \\
\hline
\end{tabular}

3

4 An example of $n_{e}$ determination is presented in Table 9 for $\mathrm{N}^{+}$at $519 \mathrm{~nm}$ and $\mathrm{H}_{\alpha}$. The data correspond to those shown in Figure 10 and Figure 13. The plasma temperature is measured by the fitting of the $\mathrm{N}^{+}$lines. Doppler broadening is negligible (below $0.01 \mathrm{~nm}$ for $\mathrm{N}^{+}$and below 0.04 $\mathrm{nm}$ for $\mathrm{H}_{\alpha}$ ) and not shown. For the composition, we consider the two cases of a fully ionized or a fully dissociated air plasma. For each composition, we estimate the Van der Waals and resonant broadening widths from the constants of Table 7. The resonant broadening is found to be negligible. The Stark broadening is obtained by subtracting the Van der Waals and resonant widths from the fitted Lorentzian width, Eq. 18.

$$
\omega_{\text {Stark }}=\omega_{\text {Lor,tot }}-\omega_{V d W}-\omega_{\text {res }}
$$

Eq. 18

The Stark broadening width is finally converted to an electron number density. No major differences arise if a fully ionized or dissociated composition is chosen. At each time step, the gas number density is determined from the measured temperature using the isentropic expansion law $\left(n_{e}^{\gamma-1} / T_{e}=c s t\right)$. At $t>100 \mathrm{~ns}$, the temperature is not measured, and the Van der Waals width is calculated at $28,000 \mathrm{~K}$. As a final remark, note that most of the previous formulas were developed in the book of Griem [54] published in 1964 (improved and corrected in [62,63]). Griem later stated (1974) that his formulas for the resonant and Van der Waals broadening widths were "very approximate" [35, p. 169] and therefore should be used only for estimation. 
Table 9 Conversion of the Lorentzian widths of $N^{+}$at $519 \mathrm{~nm}$ and $H_{\alpha}$ to electron number densities. $\omega_{\text {Lor,tot }}$ is obtained by fitting the measured lineshape with a Lorentzian line convolved with the instrumental broadening. The van der Waals contribution is then subtracted, considering a fully ionized or a fully dissociated plasma. The resonant broadening width is always negligible.

\begin{tabular}{|c|c|c|c|c|c|c|c|c|}
\hline & $\begin{array}{c}t \\
(\mathrm{~ns})\end{array}$ & $\begin{array}{c}T_{\text {gas }}(\mathrm{K}) \\
\text { gas number } \\
\text { density }\left(\mathrm{cm}^{-3}\right)\end{array}$ & $\begin{array}{c}\text { Mole fraction (\%) } \\
\mathrm{O}^{+} / \mathrm{N}^{+} / \mathrm{O} / \mathrm{N}\end{array}$ & $\begin{array}{c}\omega_{\text {Lor, tot }} \\
(\mathrm{nm})\end{array}$ & $\begin{array}{l}\omega_{V d W} \\
(\mathrm{~nm})\end{array}$ & $\begin{array}{l}\omega_{\text {Res }} \\
(\mathrm{nm})\end{array}$ & $\begin{array}{c}\omega_{\text {Stark }} \\
(\mathrm{nm})\end{array}$ & $\begin{array}{c}n_{e} \\
\left(\mathrm{~cm}^{-3}\right)\end{array}$ \\
\hline \multirow{6}{*}{$\begin{array}{l}\mathrm{N}^{+} \\
519 \\
\mathrm{~nm}\end{array}$} & \multirow{2}{*}{10} & 45,300 & $0.4 / 1.6 / 0 / 0$ & \multirow{2}{*}{4.56} & $8 \times 10^{-3}$ & $7 \times 10^{-5}$ & 4.56 & $3.0 \times 10^{19}$ \\
\hline & & $2.1 \times 10^{19}$ & $0 / 0$ / 0.4 / 1.6 & & 0.30 & 0 & 4.26 & $2.8 \times 10^{19}$ \\
\hline & \multirow{2}{*}{20} & \multirow{2}{*}{$\begin{array}{c}39,000 \\
1.1 \times 10^{19}\end{array}$} & $0.4 / 1.6 / 0 / 0$ & \multirow{2}{*}{1.57} & $8 \times 10^{-3}$ & $6 \times 10^{-5}$ & 1.56 & $1.1 \times 10^{19}$ \\
\hline & & & $0 / 0 / 0.4 / 1.6$ & & 0.13 & 0 & 1.43 & $1.0 \times 10^{19}$ \\
\hline & \multirow{2}{*}{100} & 28,200 & $0.4 / 1.6 / 0 / 0$ & \multirow{2}{*}{0.56} & $7 \times 10^{-3}$ & $4 \times 10^{-5}$ & 0.56 & $3.7 \times 10^{18}$ \\
\hline & & $3.0 \times 10^{18}$ & $0 / 0$ / $0.4 / 1.6$ & & 0.01 & 0 & 0.55 & $3.6 \times 10^{18}$ \\
\hline \multirow{5}{*}{$\begin{array}{c}\mathrm{H}_{\alpha} \\
656 \\
\mathrm{~nm}\end{array}$} & \multirow{2}{*}{20} & 38,000 & $0.4 / 1.6 / 0 / 0$ & \multirow{2}{*}{9.78} & 0.11 & $3 \times 10^{-5}$ & 9.67 & \multirow{2}{*}{$6.8 \times 10^{18}$} \\
\hline & & $1.0 \times 10^{19}$ & $0 / 0 / 0.4 / 1.6$ & & 0.11 & $3 \times 10^{-5}$ & 9.67 & \\
\hline & \multirow{2}{*}{100} & 28,200 & $0.4 / 1.6 / 0 / 0$ & \multirow{2}{*}{3.73} & 0.03 & $8 \times 10^{-5}$ & 3.70 & $1.6 \times 10^{18}$ \\
\hline & & $3.0 \times 10^{18}$ & $0 / 0 / 0.4 / 1.6$ & & 0.03 & $8 \times 10^{-5}$ & 3.70 & $1.6 \times 10^{18}$ \\
\hline & 1000 & $\begin{array}{c}28,000 \\
3.0 \times 10^{18}\end{array}$ & $0 / 0 / 0.4 / 1.6$ & 0.40 & 0.03 & $8 \times 10^{-5}$ & 0.36 & $5.4 \times 10^{16}$ \\
\hline
\end{tabular}

\section{References}

[1] Pai D Z, Lacoste D A and Laux C O 2010 Transitions between corona, glow, and spark regimes of nanosecond repetitively pulsed discharges in air at atmospheric pressure J. Appl. Phys. 107093303

[2] Pai D Z, Stancu G D, Lacoste D A and Laux C O 2009 Nanosecond repetitively pulsed discharges in air at atmospheric pressure - The glow regime Plasma Sources Sci. Technol. 18045030

[3] Stepanyan S, Minesi N, Tibère-Inglesse A C, Salmon A, Stancu G D and Laux C O 2019 Spatial evolution of the plasma kernel produced by nanosecond discharges in air J. Phys. D. Appl. Phys.

[4] Pai D Z, Lacoste D A and Laux C O 2010 Nanosecond repetitively pulsed discharges in air at atmospheric pressure-the spark regime Plasma Sources Sci. Technol. 19065015 
[5] Rusterholtz D L, Lacoste D A, Stancu G D, Pai D Z and Laux C O 2013 Ultrafast heating and oxygen dissociation in atmospheric pressure air by nanosecond repetitively pulsed discharges J. Phys. D. Appl. Phys. 46464010

[6] Popov N A 2011 Fast gas heating in a nitrogen-oxygen discharge plasma: I. Kinetic mechanism J. Phys. D. Appl. Phys. 44285201

[7] Popov N A 2016 Pulsed nanosecond discharge in air at high specific deposited energy: Fast gas heating and active particle production Plasma Sources Sci. Technol. 2544003

[8] Pai D Z 2008 Nanosecond Repetitively Pulsed Plasmas in Preheated Air at Atmospheric Pressure (Ecole Centrale Paris, PhD Thesis)

[9] Lo A, Cessou A, Lacour C, Lecordier B, Boubert P, Xu D A, Laux C O and Vervisch P 2017 Streamer-tospark transition initiated by a nanosecond overvoltage pulsed discharge in air Plasma Sources Sci. Technol. 2645012

[10] Sainct F 2014 Etude de la réactivité de décharges électriques nanoseconde à la pression atmosphérique dans la vapeur d'eau (Ecole Centrale Paris, PhD Thesis)

[11] Sainct F P, Urabe K, Pannier E, Lacoste D A and Laux C O 2020 Electron number density measurements in nanosecond repetitively pulsed discharges in water vapor at atmospheric pressure Plasma Sources Sci.

Technol.

[12] van der Horst R M, Verreycken T, van Veldhuizen E M and Bruggeman P J 2012 Time-resolved optical emission spectroscopy of nanosecond pulsed discharges in atmospheric-pressure $\mathrm{N} 2$ and N 2 / 2 O mixtures J. Phys. D. Appl. Phys. 45345201

[13] Orriere T, Moreau E and Pai D Z 2018 Ionization and recombination in nanosecond repetitively pulsed microplasmas in air at atmospheric pressure J. Phys. D. Appl. Phys. 51494002

[14] Shcherbanev S A, Yu Khomenko A, Stepanyan S A, Popov N A and Starikovskaia S M 2016 Optical emission spectrum of filamentary nanosecond surface dielectric barrier discharge Plasma Sources Sci. Technol. 26 02LT01

[15] Stepanyan S A, Starikovskiy A Y, Popov N A and Starikovskaia S M 2014 A nanosecond surface dielectric barrier discharge in air at high pressures and different polarities of applied pulses: transition to filamentary mode Plasma Sources Sci. Technol. 23045003

[16] Shcherbanev S, Ding C, Starikovskaia S M and Popov N A 2019 Filamentary nanosecond surface dielectric barrier discharge. Plasma properties in the filaments Plasma Sources Sci. Technol.

[17] Houpt A W and Leonov S B 2016 Charge Transfer in Constricted Form of Surface Barrier Discharge at Atmospheric Pressure J. Thermophys. Heat Transf. 31 1-9

[18] Shao T, Zhang C, Niu Z, Yan P, Tarasenko V F, Baksht E K, Kostyrya I D and Shutko V 2011 Runaway electron preionized diffuse discharges in atmospheric pressure air with a point-to-plane gap in repetitive pulsed mode J. Appl. Phys. 109

[19] Shao T, Tarasenko V F, Zhang C, Lomaev M I, Sorokin D A, Yan P, Kozyrev A V. and Baksht E K 2012 Spark discharge formation in an inhomogeneous electric field under conditions of runaway electron generation J. Appl. Phys. 111

[20] Stritzke P, Sander I and Raether H 1977 Spatial and temporal spectroscopy of a streamer discharge in nitrogen J. Phys. D. Appl. Phys. 10 2285-300

[21] Albrecht H, Herden W H, Maly R, Saggau B, Wagner E, Bloss W H, Herden W H, Maly R, Saggau B and Wagner E 1977 New Aspects on Spark Ignition SAE-770853

[22] Parkevich E V., Khirianova A I, Agavonov A V., Tkachenko S I, Mingaleev A R, Shelkovenko T A, Oginov A V. and Pikuz S A 2018 Anode Plasma Formation at the Initial Stage of a Nanosecond Air Discharge J. Exp. Theor. Phys. 126 422-9 
[23] Parkevich E, Medvedev M, Ivanenkov G, Khirianova A, Selyukov A, Agafonov A, Korneev P, Gus'kov S and Mingaleev A 2019 Fast fine-scale spark filamentation and its effect on the spark resistance Plasma Sources Sci. Technol.

[24] Parkevich E V, Medvedev M A, Agafonov A V, Tkachenko S I, Oginov A V, Khirianova A I, Mingaleev A R, Shelkovenko T A and Pikuz S A 2018 The peculiarities of near-cathode processes in air discharge at atmospheric pressure

[25] Barreto E, Jurenka H and Reynolds S I 1977 The formation of small sparks J. Appl. Phys. 48 4510-20

[26] Raizer Y P 1991 Gas Discharge Physics ed J E Allen (Springer Verlag. Berlin.)

[27] Minesi N, Mariotto P, Stancu G D and Laux C O 2020 Role of the excited electronic states in the ionization of ambient air by a nanosecond discharge AIAA Scitech 2020 Forum

[28] Rusterholtz D 2012 Nanosecond Repetitively Pulsed Discharges in Atmospheric Pressure Air (Ecole Centrale Paris, PhD Thesis)

[29] Dumitrache C, Gallant A, Minesi N, Stepanyan S, Stancu G D and Laux C O 2019 Hydrodynamic Regimes Induced by Nanosecond Pulsed Discharges in Air: Mechanism of Vorticity Generation J. Phys. D. Appl. Phys.

[30] Pannier E 2019 Conversion of carbon dioxyde with nanosecond repetitive discharges (CentraleSupélec, $\mathrm{PhD}$ Thesis)

[31] Kramida A, Reader J, Ralchenko Y and NIST ASD Team 2018 NIST ASD NIST At. Spectra Database (ver. 5.6.1)

[32] Orriere T 2018 Confinement micrométrique des décharges pulsées nanosecondes dans l'air à pression atmosphérique et effets électro-aérodynamiques (Université de Poitiers, PhD Thesis, in French)

[33] www.spectralfit.com [Online] Specair 3.0

[34] Laux C O, Spence T G, Kruger C H and Zare R N 2003 Optical diagnostics of atmospheric pressure air plasmas Plasma Sources Sci. Technol. 12 125-138

[35] Griem H R 1974 Spectral Line Broadening by Plasmas (New York: ACADEMIC PRESS, INC.)

[36] Sher E, Ben-Ya'ish J and Kravchik T 1992 On the birth of spark channels Combust. Flame 89 186-94

[37] Gigosos M A, González M Á and Cardeñoso V 2003 Computer simulated Balmer-alpha, -beta and -gamma Stark line profiles for non-equilibrium plasmas diagnostics Spectrochim. Acta - Part B At. Spectrosc. 58 1489-504

[38] Konjević N, Lesage A, Fuhr J R, Wiese W L, Konjevi'c N, Fuhr J R, Lesage A and Wiese W L 2002 Experimental Stark widths and shifts for spectral lines of neutral and ionized atoms (a critical review of selected data for the period 1989 through 2000) J. Phys. Chem. Ref. Data 31 819-927

[39] Capitelli M, Ferreira C M, Gordiets B F and Osipov A I 2000 Plasma Kinetics in Atmospheric Gases vol 31 (Berlin, Heidelberg: Springer Berlin Heidelberg)

[40] Colonna G, D'Angola A and Capitelli M 2012 Electronic excitation and isentropic coefficients of high temperature planetary atmosphere plasmas Phys. Plasmas 19072115

[41] McBride B J and Gordon S 1992 Computer program for calculating and fitting thermodynamic functions

[42] Phuoc T X 2005 An experimental and numerical study of laser-induced spark in air Opt. Lasers Eng. 43 $113-29$

[43] Shneider M N 2006 Turbulent decay of after-spark channels Phys. Plasmas 13 1-11

[44] Ciccarino C J and Savin D W 2019 Electron-impact ionization of atomic nitrogen J. Thermophys. Heat 
Transf. 33 154-62

[45] Stepanyan S, Hayashi J, Salmon A, Stancu G D and Laux C O 2017 Large-volume excitation of air, argon, nitrogen and combustible mixtures by thermal jets produced by nanosecond spark discharges Plasma Sources Sci. Technol. $2622-4$

[46] Kono M, Niu K, Tsukamoto T and Ujiie Y 1989 Mechanism of flame kernel formation produced by short duration sparks Symposium (International) on Combustion vol 22 (Elsevier) pp 1643-9

[47] Olsen H L, Edmonson R B and Gayhart E L 1952 Microchronometric Schlieren Study of Gaseous Expansion from an Electric Spark J. Appl. Phys. 23 1157-62

[48] Bane S P M, Ziegler J L and Shepherd J E 2015 Investigation of the effect of electrode geometry on spark ignition Combust. Flame 162 462-9

[49] Xu D 2013 Thermal and hydrodynamic effects of nanosecond discharges in air and application to plasmaassisted combustion (Ecole Centrale Paris, PhD Thesis)

[50] Wang Y, Zatsarinny O and Bartschat K 2014 B-spline R-matrix-with-pseudostates calculations for electronimpact excitation and ionization of nitrogen Phys. Rev. A $\mathbf{8 9} 062714$

[51] Maly R R and Herweg R 2008 Spark Ignition and Combustion in Four-Stroke Gasoline Engines Flow and Combustion in Reciprocating Engines (Springer) pp 1-66

[52] Minesi N, Stepanyan S A, Mariotto P B, Stancu G-D and Laux C O 2019 On the arc transition mechanism in nanosecond air discharges AIAA Scitech 2019 Forum

[53] Lacour C, Lo A, Marrero J, Lefebvre F, Vervisch P, Cessou A and Lecordier B 2016 Characterisation of electric discharge in laminar flow with optical diagnostics 18th Int. Symp. Appl. Laser Imaging Tech. to Fluid Mech.

[54] Griem H R 1964 Plasma spectroscopy (McGraw-Hill Book Company)

[55] Griem H R 1997 Principles of plasma spectroscopy

[56] Allard N and Kielkopf J 1982 The effect of neutral nonresonant collisions on atomic spectral lines Rev. Mod. Phys. 54 1103-82

[57] Kelleher D E 1981 Stark broadening of visible neutral helium lines in a plasma J. Quant. Spectrosc. Radiat. Transf. 25 191-220

[58] Laux C O 1993 Optical Diagnostics and Radiative Emission of Air Plasmas (Stanford University, PhD Thesis)

[59] Djurovi'c S and Konjevi'c N 2009 On the use of non-hydrogenic spectral lines for low electron density and high pressure plasma diagnostics Plasma Sources Sci. Technol. 18 1-8

[60] McQuarrie J D S 2014 McQuarrie: Physical Chemistry: A molecular approach

[61] Field G B, Somerville W B and Dressler K 1966 Hydrogen Molecules in Astronomy Annu. Rev. Astron. Astrophys. 4 207-44

[62] Ali A W and Griem H R 1965 Theory of resonance broadening of spectral lines by atom-atom impacts Phys. Rev. 140891

[63] Ali A W and Griem H R 1965 [Errata] Theory of resonance broadening of spectral lines by atom-atom impacts Phys. Rev. 140891

[64] Castera P 2015 Energy coupling mechanisms in pulsed surface discharges for flow control (Ecole Centrale Paris, PhD Thesis)

[65] Drake G W F 2006 Atomic, Molecular, and Optical Physics 
[66] Allard N F, Kielkopf J F, Cayrel R and van't Veer-Menneret C 2008 Self-broadening of the hydrogen Balmer $\alpha$ line Astron. Astrophys. 480581

[67] Gigosos M A, Cardeñoso V, At J P B, Opt M, Cardeñoso V, Antonio M and Gigosos M A 1996 New plasma diagnosis tables of hydrogen Stark broadening including ion dynamics J. Phys. B At. Mol. Opt. Phys. 29 4795-838

[68] Konjević N, Ivković M and Sakan N 2012 Hydrogen Balmer lines for low electron number density plasma diagnostics Spectrochim. Acta Part B At. Spectrosc. 76 16-26

[69] Mar S, Aparicio J A, Rosa M I de la, Val J A del, Gigosos M A, González V R and Pérez C 2000 Measurement of Stark broadening and shift of visible N II lines J. Phys. B At. Mol. Opt. Phys. 33 1169-84

[70] Rivière P 2002 Systematic semi-classical calculations of Stark broadening parameters of NI, OI, NII, OII multiplets for modelling the radiative transfer in atmospheric air mixture plasmas J. Quant. Spectrosc. Radiat. Transf. 73 91-110

[71] Babický V, Lukeš P, Šimek M, Člupek M and Pongrác B 2018 Spectroscopic characteristics of H $\alpha$ /O I atomic lines generated by nanosecond pulsed corona-like discharge in deionized water J. Phys. D. Appl. Phys. 51124001 